\title{
Selective Removal of Organonitrogen Compounds in Fuel using Functional Polybenzimidazole Nanofibres: A Combined Experimental and Theoretical Study
}

\author{
M.S. Abdul-quadir, R. van der Westhuizen ${ }^{\mathrm{b}}$, W. Welthagen ${ }^{\mathrm{b}}$, E.E. Ferg, \\ Z.R. Tshentu a and A.S. Ogunlaja ${ }^{a, k}$ \\ ${ }^{a}$ Department of Chemistry, Nelson Mandela University, P.O. Box 77000, Port Elizabeth, 6031, South Africa. \\ ${ }^{b}$ Analytical Technology, Sasol Technology (Pty) Limited, P.O. Box 1, Sasolburg, 1947, South Africa.
}

Received 14 September 2018, revised 13 May 2019, accepted 14 May 2019.

\begin{abstract}
Organonitrogen compounds present in fuel oils are deleterious to the environment as well as refining catalysts. Herein, functional polybenzimidazole (PBI) nanofibres fabricated in the presence of $\mathrm{N}$-compounds (nitrogen-containing compounds) were employed for the selective adsorption of quinoline, pyrimidine and carbazole, largely found in diesel fuel. Adsorption capacities of $11.5 \mathrm{mg} \mathrm{g}^{-1}, 11.8 \mathrm{mg} \mathrm{g}^{-1}$ and $11.0 \mathrm{mg} \mathrm{g}^{-1}$ were observed for pyrimidine, carbazole and quinoline, respectively. Density functional theory (DFT) studies indicated $\pi-\pi$ interactions/stacking and hydrogen bond interactions between the nitrogen atom of $\mathrm{N}$-compounds and PBI. The study clearly shows the potential of PBI material use for the selective removal of organonitrogen compounds in fuels.
\end{abstract}

KEYWORDS

Organonitrogen compounds, polybenzimidazole (PBI), Adsorptive denitrogenation, DFT calculations.

\section{Introduction}

Fuel oils are widely used as a source of energy required in the transportation and industrial sectors. Feedstock currently employed for present and future energy requirements are of low-grade and tends to have higher organo-sulfur, -oxygen and -nitrogen compounds. Of interest is the deleterious effect of organonitrogen compounds in fuel such as colouration of fuel, deactivation of refining catalysts and catalytic converters in motor vehicles. ${ }^{1-5}$ Organonitrogen compounds in fuel oil mostly comprises of: (i) pyridine and its benzologues (pyrimidine and quinoline) and (ii) pyrrole benzologues such as indoles and carbazoles. $^{5-8}$

Hydro-denitrogenation (HDN) process currently employed for the removal of organonitrogen compounds in fuels is effective for the removal of non-refractory organonitrogen compounds and its derivatives. ${ }^{9}$ At extreme HDN conditions, refractory compounds are eliminated alongside some aromatic contents of fuel, thereby altering fuel specifications. ${ }^{9,10}$

Due to limitations suffered by the HDN process, adsorptive denitrogenation is a promising complementary step to hydrodenitrogenation to achieving the anticipated nitrogen limit in fuels. ${ }^{9,11-13}$ The use of solvents such as acetonitrile and ethanol for the extraction of refractory organonitrogen compounds in adsorptive denitrogenation has resulted in fuel properties being altered as well as the inability to recycle extraction solvents as most solvents possess similar properties (e.g. boiling point) with the extracted compounds. ${ }^{15}$ Selective sorbent by means of molec- ularly imprinted polymers (MIPs) have been developed to remove several sulfur and nitrogen-containing compounds in fuels. ${ }^{14-16}$ In a study reported by Cao et al. ${ }^{15}$ indole-imprinted polymer showed selectivity for indole with an adsorption capacity of $31.80 \mathrm{mg} \mathrm{g}^{1}$. Imprinted polymer also offered fast adsorption kinetics of $90 \mathrm{~min}$ to reach adsorption equilibrium. In a similar study, $\mathrm{SiO}_{2} @ \mathrm{MIPs}$ gave an adsorption capacity of $60 \mathrm{mg} \mathrm{g}^{-1}$ for carbazole. $^{16}$

Polymer-based nanofibre offers large surface area-to-volume ratio and high porosity, thus making it a good material for several applications, which includes adsorbents for selective adsorption, ${ }^{14}$ colorimetric sensing materials, ${ }^{17}$ and catalyst support. ${ }^{18}$ Generally, research interest in adsorbent development is mainly concentrated on the functionality of the pore surface and the design of pore size and geometry. ${ }^{19}$

To the best of our knowledge, polybenzimidazole-based nanofibres have not been prepared as adsorbents for the removal of refractory organonitrogen compounds. Herein, we describe a combination of experimental and theoretical studies for the adsorption of selected nitrogen-containing compounds in fuel. In the present work, N-compounds were introduced into PBI solution prior to electrospinning for formation of the adsorbent. PBI is a multifunctional polymer containing large number of $-\mathrm{NH}$, imine and aromatic groups capable of self-assembly with molecules such as quinoline, carbazole and pyrimidine (Fig. 1) through forming hydrogen bonds and $\pi-\pi$ interactions. The functional groups in the polymer networks equivalently conju-

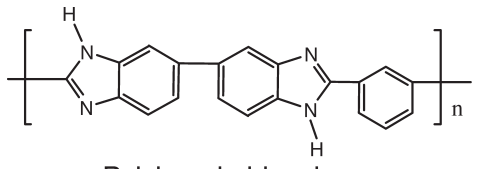

Polybenzimidazole

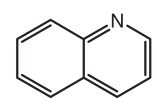

Quinoline

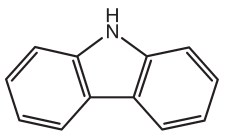

Carbazole<smiles>c1cncnc1</smiles>

Pyrimidine

Figure 1 Molecular structure of polybenzimidazole, quinoline, carbazole and pyrimidine. 
gate with the targeted molecules, leading to a remarkable adsorption capacity. Additionally, the voids and mesoporous channels within the polymer chain provides a high contact area and fast diffusion path for the adsorption and subsequent desorption of the targeted molecules, N-compounds. Furthermore, the excellent mechanical and thermal strength of PBI is beneficial for its separation, regeneration and reuse.

\section{Experimental Section}

\subsection{Materials}

Polybenzimidazole (PBI) (Charlotte, USA), lithium bromide (LiBr), Triton $\mathrm{X}-114$, quinoline, carbazole and pyrimidine, $N, N$-dimethylacetamide (DMA), naphthalene, acetonitrile and methanol were purchased from Sigma-Aldrich/Merck, South Africa.

\subsection{Instrumentation}

TESCAN Vega TS 5136LM scanning electron microscope was employed to image the various PBI nanofibres. Before images were taken, the nanofibres were gold-coated to prevent surface charging and to protect the surface material from thermal damage by the electron beam. TriStar II 3020 3.02, Surface Area and Porosity Analyzer was employed for BET surface area measurement by using $\mathrm{N}_{2}$ adsorption/desorption isotherms at $77 \mathrm{~K}$. Prior to each measurement, nanofibres were degassed at $60^{\circ} \mathrm{C}$ for $24 \mathrm{~h}$. Adsorption of model $\mathrm{N}$-compound and fuel oil were monitored by employing gas chromatograph fitted with flame ionization detector (GC-FID) and LECO Pegasus GCxGC-HRT respectively. The GC conditions for model fuel analyses is as follows: Oven temperature of $50^{\circ} \mathrm{C}$ ramped to $80^{\circ} \mathrm{C}$ for $2 \mathrm{~min}$, and then increased to $300{ }^{\circ} \mathrm{C}$ at a rate of $20^{\circ} \mathrm{C} \mathrm{min}^{-1}$, and finally held for $1 \mathrm{~min}$. LECO Pegasus GCXGC-HRT was employed to monitor the adsorption of organonitrogen compounds in diesel.; Injection: Split Injection (100:1) at $250{ }^{\circ} \mathrm{C}$; Primary Column: Stabilwax (Restek), $30 \mathrm{~m} \times 250 \mu \mathrm{m}(0.25 \mu \mathrm{m})$; Secondary Column: Rxi-5 (Restek), $1.5 \mathrm{~m} \times 100 \mu \mathrm{m}(0.1 \mu \mathrm{m})$; Carrier Gas: Helium, $1.2 \mathrm{~mL} \mathrm{m^{-1 }}$ constant flow; Primary Oven Program: $40{ }^{\circ} \mathrm{C}$ (0.1 min) to $260^{\circ} \mathrm{C}(78.4 \mathrm{~min})$ at $3^{\circ} \mathrm{C} \mathrm{min}^{-1}$; Secondary Oven Program: $45^{\circ} \mathrm{C}(0.1 \mathrm{~min})$ to $265^{\circ} \mathrm{C}(56 \mathrm{~min})$ at $3^{\circ} \mathrm{C} \mathrm{min}{ }^{-1}$; Modulator Offset: $15^{\circ} \mathrm{C}$; Modulation Frequency: $8 \mathrm{sec}$; Hot Time: 2 sec; MS: LECO Pegasus GCxGC-HRT; Ionization: Electron Ionization at $70 \mathrm{eV}$; Source Temperature: $250{ }^{\circ} \mathrm{C}$; Stored Mass Range: 30 to $500 \mathrm{u}$; Acquisition Rate: 100 spectra $\mathrm{sec}^{-1}$. Thermogravimetric analysis-Fourier-transform infrared (TGA-FTIR) was employed to examine the thermal decomposition of functional PBI polymers is discussed as follows. TGA experiments that were done using a constant heating rate of $20{ }^{\circ} \mathrm{C} \mathrm{min}^{-1}$. The furnace purge gas exhaust from the TGA (Perkin Elmer STA 6000) was connected by a heated stainless-steel transfer line to the TGA interface module of the FTIR spectrometer (Perkin Elmer UATR). The

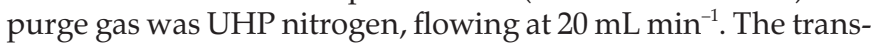
fer line temperature was set at $300{ }^{\circ} \mathrm{C}$. The TGA-FTIR interface module in the auxiliary experiment compartment of the FTIR spectrometer was maintained at $300{ }^{\circ} \mathrm{C}$. The spectrometer provided concurrent chemical analysis of evolved gases. Both differential scanning calorimetry (DSC) and simultaneous TGA-DSC were used to examine enthalpy changes during decomposition. Perkin Elmer DSC was used for temperature ranges from $50{ }^{\circ} \mathrm{C}$ to $600{ }^{\circ} \mathrm{C}$. Isothermal titration calorimetry (ITC) experiments were carried out at $25^{\circ} \mathrm{C}$ by titrating $700 \mu \mathrm{L}$ of PBI solution $\left(1 \mathrm{mg} \mathrm{mL}^{-1}\right)$ in ampoule against $200 \mu \mathrm{L} \mathrm{N}$ compounds $\left.(20 \mu \mathrm{mol} \mathrm{dm})^{-3}\right)$ with an injection volume of $5 \mu \mathrm{L}$ and at a stirrer speed of $40 \mathrm{rpm}$ on a TAMIII nanocalorimeter. The reference cell was kept empty.

\subsection{Fabrication and Electrospinning of Polybenzimidazole Nanofibres}

The technique employed for the fabrication and electrospinning of PBI nanofibres is similar to the method reported in our previous study. ${ }^{14}$ First, $2.0 \mathrm{~g}$ of PBI was dissolved in $10 \mathrm{~mL}$ DMA containing $0.4 \mathrm{~g}(4 \% \mathrm{wt}) \mathrm{LiBr}$ under reflux condition for $5 \mathrm{~h}$. The resulting viscous solution was cooled, followed by the removal of undissolved particulates via filtration. Next, $0.01 \mathrm{M}$ $(1 \mathrm{~mL})$ of nitrogen-containing compounds (quinoline, pyrimidine and carbazole) in $50 \mu \mathrm{L}$ Triton X-114 was added to dissolved PBI solution separately, after which the mixture was further stirred at $50^{\circ} \mathrm{C}$ for $4 \mathrm{~h}$ to form a homogeneous mixture.

The resulting solution was electrospun by using the following optimized electrospinning conditions: a voltage of between 22 and $25 \mathrm{kV}$ at a flow-rate of $0.2 \mathrm{~mL} \mathrm{~h}^{-1}$, with a distance between the needle tip and collector plate placed at $15 \mathrm{~cm}$. Nitrogen compounds (quinoline, pyrimidine and carbazole) were removed by washing the nanofibres with a mixture of warm methanol and acetonitrile (1:1) until no templates and residual solvent (DMA) was detected on the GC-FID. The washed nanofibres were later dried overnight under vacuum. Scheme 1 illustrates the steps employed in the fabrication of functional PBI nanofibres.

\subsection{Theoretical Studies}

Molecular interactions between polybenzimidazole (PBI) and the various nitrogen compounds (quinoline, carbazole and pyrimidine) were modelled. The atomic level interaction of the various nitrogen compounds (quinoline, carbazole and pyrimidine) with polybenzimidazole (PBI) was predicted by using B3LYP functional with a basis set $6-311 G++(d, p)$ using Gaussian09 (calculated at 298K). ${ }^{20}$ The interactions on a molecular level depend basically on the following interactions, and these are HOMO and LUMO orbital interactions, $\pi-\pi$ interactions, hydrogen bonding and van der Waals forces. Other electronic parameters calculated are hardness $(\eta)$, softness $(\sigma)$, electronegativity $(\chi)$ and chemical potential $(\mu) .{ }^{21}$ According to the Koopmans theorem, the ionization energies (I) and the electron affinities (A) of molecules and adducts were calculated by employing the equations below;

$$
\begin{aligned}
& \mathrm{I}=-\mathrm{E}_{\text {Hомо }} \\
& \mathrm{A}=-\mathrm{E}_{\text {LUMO }}
\end{aligned}
$$

Therefore, LUMO-HOMO energy gap $(\Delta \mathrm{E})=\mathrm{E}_{\text {LUMO }}-\mathrm{E}_{\text {Hомо }}$. The equation for enthalpies, Gibb's free energies and entropy of formation was obtained by using Eqs. $1 \& 2$.

$$
\Delta \Delta \mathrm{H}_{\text {adduct }}=\Delta \mathrm{H}_{\text {adduct }}-\left(\mathrm{m} \Delta \mathrm{H}_{\mathrm{PBI}}+\mathrm{t} \Delta \mathrm{H}_{\mathrm{NCs}}\right)
$$

where PBI and NCs are polybenzimidazole and nitrogen-containing compounds, respectively.

$$
\Delta \Delta \mathrm{G}_{\text {adduct }}=\Delta \Delta \mathrm{H}_{\text {adduct }}-\mathrm{T} \Delta \Delta \mathrm{S}_{\text {adduct }}
$$

$\Delta \Delta \mathrm{G}, \mathrm{T}$ and $\Delta \Delta \mathrm{S}$ are the Gibbs free energy, temperature $\left(25^{\circ} \mathrm{C}\right)$ and entropy for adduct formation at standard conditions, respectively.

\subsection{Thermodynamic Parameters using Van't Hoff Plot}

Derived Van't Hoff plot was employed to determine the experimental enthalpies, entropies and Gibb's free energies of adsorption between PBI and N-compounds. ${ }^{22}$ Briefly, a combination of adsorption Gibbs free energy change $\left(\Delta \mathrm{G}^{\circ}\right.$ ad $)$ gives (Eq. 3):

$$
\ln K_{a d}=-\Delta G_{\text {ad }}^{\circ} / R T=\Delta S^{\circ} / \mathrm{R}-\Delta H^{\circ} / R T
$$

where $\Delta \mathrm{G}_{\text {ad }}^{\circ}$ is the free energy change $\left(\mathrm{kJ} \mathrm{mol}^{-1}\right), \Delta \mathrm{H}^{\circ}$ is the change in enthalpy $\left(\mathrm{kJ} \mathrm{mol}^{-1}\right), \Delta \mathrm{S}^{\circ}$ is the entropy change $\left(\mathrm{kJ} \mathrm{mol}^{-1}\right.$ $\left.\mathrm{K}^{-1}\right)$, $\mathrm{T}$ is the absolute temperature $(\mathrm{K})$ and $\mathrm{R}$ is the universal gas constant $\left(8.314 \mathrm{~J} \mathrm{~mol}^{-1} \mathrm{~K}^{-1}\right)$. Thus, $\Delta \mathrm{H}^{\circ}$ can be determined from 


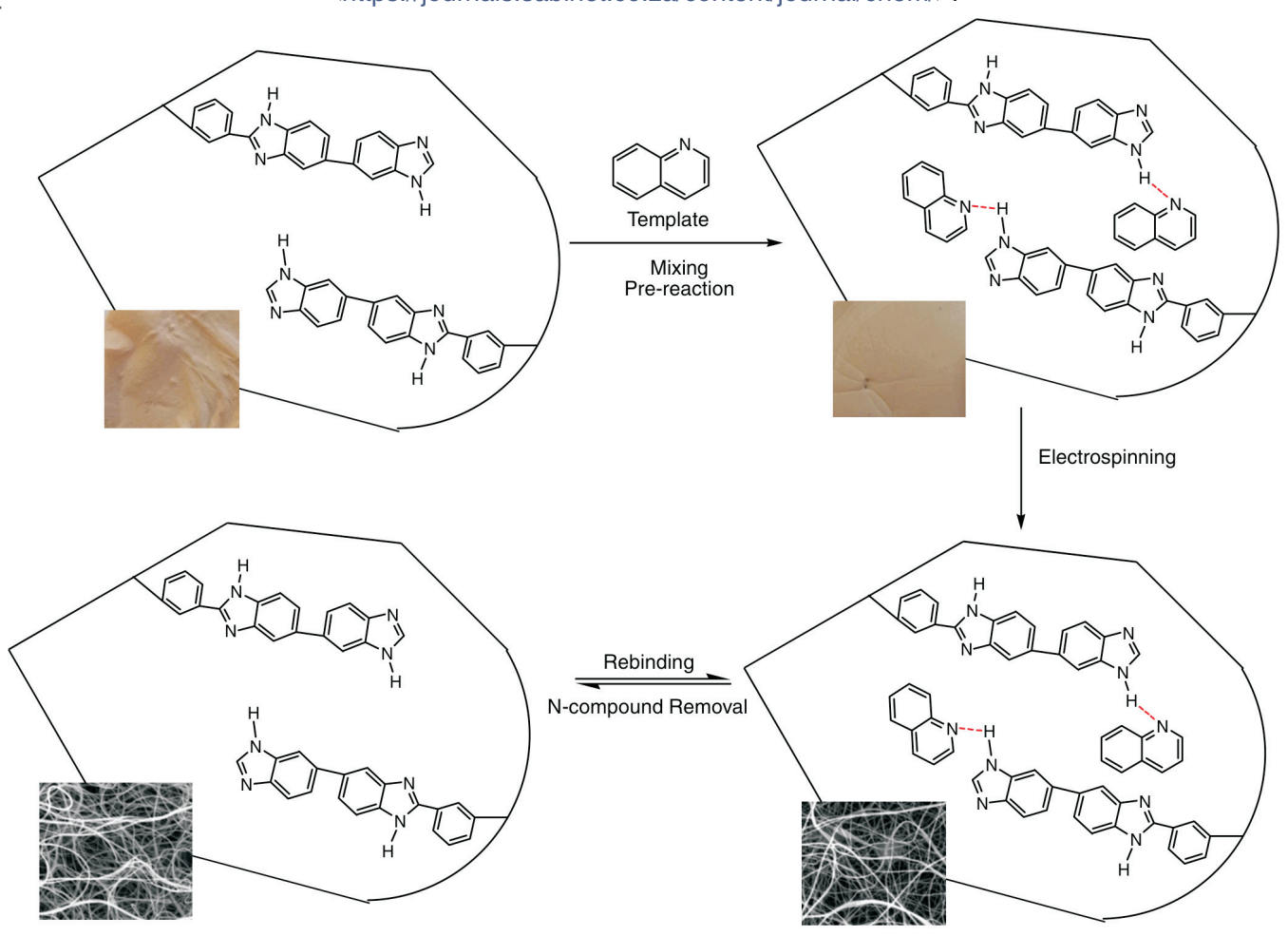

Functional PBI nanofibers

Scheme 1

Scheme for the fabrication of functional polybenzimidazole (PBI) nanofibres.

the slope $\left(-\Delta \mathrm{H}^{\circ} / \mathrm{R}\right)$ of the linear Van't Hoff plot i.e. in $\mathrm{K}_{\mathrm{ad}}$ versus $(1 / T),{ }^{22}$ while $\Delta S^{\circ}$ is obtained from the intercept $\left(\Delta S^{\circ} / R\right)$. For this experiment, Van't Hoff experiments for all $\mathrm{N}$-compounds were carried out at $30,35,40$ and $45^{\circ} \mathrm{C}$ by using batch adsorption process.

\subsection{Batch Adsorption}

Pre-conditioned PBI nanofibres $(50 \mathrm{mg})$ were placed in a capped vial containing $5 \mathrm{~mL}$ of organonitrogen compounds $\left(120 \mathrm{mg} \mathrm{L}^{-1}\right)$. The mixture was agitated mechanically at $150 \mathrm{rpm}$ for $7 \mathrm{~h}$. Progress in the adsorption of the various nitrogen compounds were followed by withdrawing aliquots for measurement at even time interval. Adsorption capacity, $\mathrm{q}_{\mathrm{e}}\left(\mathrm{mg} \mathrm{g}^{-1}\right)$ was calculated from Eq. 4.

$$
\mathrm{q}_{\mathrm{e}}=\frac{\mathrm{V}\left(\mathrm{C}_{\mathrm{o}}-\mathrm{C}_{\mathrm{e}}\right)}{\mathrm{W}}
$$

where $\mathrm{C}_{\mathrm{o}^{\prime}} \mathrm{C}_{\mathrm{e}}, \mathrm{W}$ and $\mathrm{V}$ are the initial concentration $\left(\mathrm{mg} \mathrm{L}^{-1}\right)$, equilibrium concentration $\left(\mathrm{mg} \mathrm{L}^{-1}\right)$, nanofibre mass (grams) and volume (in litres), respectively.

\subsubsection{Solid Phase Extraction (SPE)}

Adsorption studies for the removal of organonitrogen compounds was carried out by weighing $150 \mathrm{mg}$ of PBI nanofibres (comprising of $50 \mathrm{mg}$ quinoline-based, $50 \mathrm{mg}$ carbazole-based and $50 \mathrm{mg}$ pyrimidine-based nanofibres) as adsorbent. Adsorption proceeded under SPE manifold by conditioning nanofibres at a vacuum pressure of $20 \mathrm{inHg}$ with a solution of hexane followed by loading the hydrotreated diesel $(3 \mathrm{~mL}$ hydrotreated diesel). Cyclohexane was employed to wash interfering molecules from the sorbent and finally $\mathrm{N}$-compounds were eluted by using a mixture of acetonitrile:methanol (1:1).

Selectivity factor (Eq. 5) ${ }^{23}$ was employed for the determination of adsorption selectivity of the various adsorbents. The selectivity factor formula is provided in Eq. 5.

$$
\alpha_{\mathrm{i}-\mathrm{r}}=\left(\mathrm{q}_{\mathrm{i}} / \mathrm{q}_{\mathrm{r}}\right) \div\left(\mathrm{C}_{\mathrm{e}, \mathrm{i}} / \mathrm{C}_{\mathrm{e}, \mathrm{r}}\right)
$$

where $\mathrm{q}_{\mathrm{i}}$ and $\mathrm{q}_{\mathrm{r}}$ are the adsorption capacities of the compound $\mathrm{i}$ and the reference compound $\mathrm{r}$ at equilibrium, respectively. $\mathrm{C}_{e, i}$ and $\mathrm{C}_{\mathrm{e}, \mathrm{r}}$ are the equilibrium concentrations of compound $\mathrm{i}$ and the reference compound $r$, respectively. Naphthalene was selected as a reference compound as it is a predominant poly aromatic hydrocarbon (PAH) present in fuel.

\section{Results and Discussion}

\subsection{Material Characterization}

\subsubsection{Thermogravimetric Analysis (TGA)}

Thermogravimetric analysis of pristine nanofibres (P-PBI), carbazole-based nanofibres (CAR-PBI), quinoline-based nanofibres (QUN-PBI) and pyrimidine-based PBI nanofibres (PYMPBI) are provided in Fig. 2. All PBI nanofibres presented two distinct weight loss decomposition patterns at $50-135{ }^{\circ} \mathrm{C}$ and $136-580^{\circ} \mathrm{C}$. In pristine PBI nanofibre, the gradual loss of bound and unbounded solvent molecules was observed in the first decomposition temperatures $\left(50-135^{\circ} \mathrm{C}\right)$ with a total weight loss of $10 \% .{ }^{15,24}$ This was immediately followed by the gradual decomposition of the polymer occurring between 136 and $580{ }^{\circ} \mathrm{C}$ (weight loss $=8 \%$ ). A total of weight loss of $18 \%$ occurred, thus indicating a highly stable adsorbent material. ${ }^{15}$

For QUN-PBI nanofibres, a weight loss of $9.1 \%$ was observed at temperatures between 50 and $136{ }^{\circ} \mathrm{C}$ and attributed to moisture and solvent molecules loss. It was immediately followed by a gradual degradation of quinoline-PBI backbone (8.7 \% weight loss between 137 and $580^{\circ} \mathrm{C}$ ).

The TGA degradation of PYM-PBI nanofibres resulted in weight loss of $10.2 \%$ in the first decomposition profile $\left(50-137^{\circ} \mathrm{C}\right)$, a further $6.1 \%$ weight loss observed between 138 and $580{ }^{\circ} \mathrm{C}$ resulted partial degradation of pyrimidine-PBI nanofibres.

TGA analysis of CAR-PBI nanofibres presented a weight loss of $5.8 \%$ attributed to the elimination of bonded and non-bonded 
S. Afr. J. Chem., 2019, 72, 88-100,

<https://journals.sabinet.co.za/content/journal/chem/>.
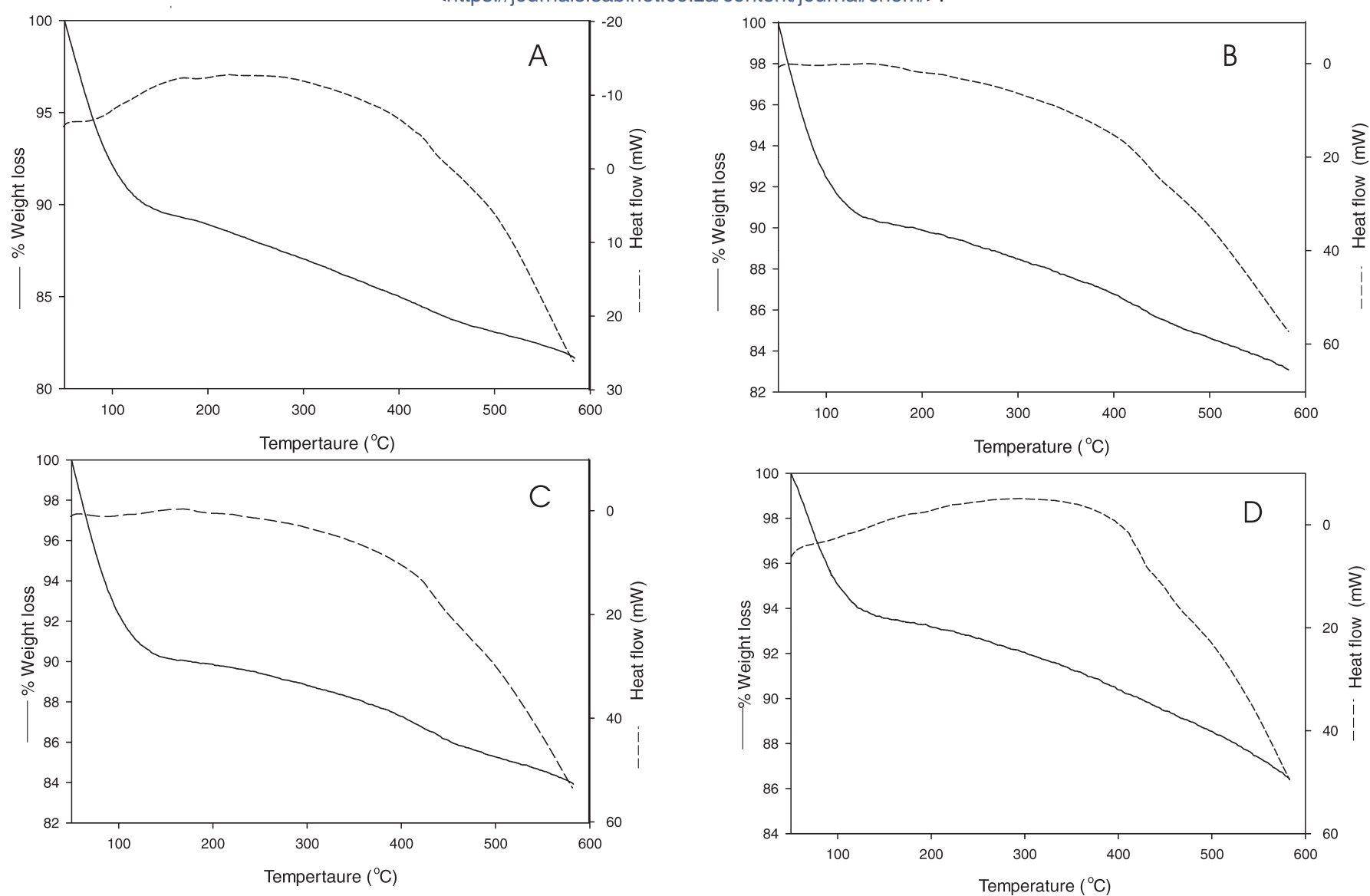

Figure 2 TGA-DSC profiles of pristine nanofibres (P-PBI) (A), pyrimidin-based PBI nanofibres (PYM-PBI) (B), quinoline-based nanofibres (QUN-PBI) (C), and carbazole-based nanofibres (CAR-PBI) (D).

solvents at a range of $50-122^{\circ} \mathrm{C}$, and a further $7.2 \%$ weight loss observed between 125 and $580^{\circ} \mathrm{C}$. DSC thermogram for all polymers obtained under nitrogen gas environment show low exothermic behaviour during decomposition (Figs. 2a,b,c,d). TGA thermograms indicated that PBI nanofibres displayed somewhat similar degradation profiles, this is probably due to similar pores (cavities) within the material, and thermodynamic properties of PBI. ${ }^{24-28}$ FT-IR interfaced with TGA confirmed the release of small quantities of $\mathrm{CO}_{2}, \mathrm{H}_{2} \mathrm{O}$ and methane gas at 2294$2388 \mathrm{~cm}^{-1}, 1727-1745 \mathrm{~cm}^{-1}$ and $2920-2950 \mathrm{~cm}^{-1}$, respectively, during the degradation of PBI polymers (Fig. 3).

\subsubsection{Scanning Electron Microscopy (SEM) and \\ Electron Dispersive X-ray (EDX)}

The SEM micrographs of PBI nanofibres after washing are presented in Fig. 4. Varying diameter ranges were observed with all pristine PBI nanofibres $(2.00-3.80 \mu \mathrm{m})$, quinoline-based PBI nanofibres $(2.50-3.80 \mu \mathrm{m})$, pyrimidine-based PBI nanofibres $(1.80-3.50 \mu \mathrm{m})$ and carbazole-based PBI nanofibres $(1.50-2.50 \mu \mathrm{m})$. As shown, surface morphological integrity of the various nanofibres was preserved even after washing the nitrogen-containing compounds off the polybenzimidazole nanofibres. SEM images confirmed varying diameter sizes, morphology changes could not be ascertained from the images (Fig. 4). ${ }^{29}$

Electron dispersive X-ray (EDX) spectroscopic studies showed the formation of varying nitrogen contents on the functional PBI nanofibres (Fig. 5). Qualitative measurement of nitrogen levels (atomic \%) in pristine nanofibres (P-PBI), carbazole-based nanofibres (CAR-PBI), quinoline-based nanofibres (QUN-PBI) and pyrimidine-based PBI nanofibres (PYM-PBI) was 16.56, 3.91, 6.65 and $3.06 \%$, respectively. Similarly, all PBI nanofibres showed the presence of $\mathrm{Br}$, and this was due to the addition of $\mathrm{LiBr}$ to PBI polymer prior to electrospinning.

\subsubsection{BET Surface Area}

Surface area of pristine PBI nanofibres (P-PBI), carbazole-based PBI nanofibres (CAR-PBI), quinoline-based PBI nanofibres (QUN-PBI) and pyrimidine-based PBI nanofibres (PYM-PBI) with well-defined pore diameters of $(49 \pm 10 \AA$ or $4.9 \pm 1.0 \mathrm{~nm})$; $(52 \pm 4 \AA$ or $5.2 \pm 0.4 \mathrm{~nm}) ;(48 \pm 6 \AA$ or $4.8 \pm 0.6 \mathrm{~nm})$ and $(51 \pm 7 \AA$ or $5.1 \pm 0.7 \mathrm{~nm})$, respectively, falls within the mesopore region $(2 \mathrm{~nm}<$ pore diameter $<50 \mathrm{~nm})$ (Table 1$){ }^{30}$

It was observed that surface area of nanofibres decreased upon formation of nitrogen-containing compound based PBI nanofibres. The drop-in surface area was attributed to the well-resolved hysteresis loop in functional PBI nanofibres (Fig. S1)..$^{25,26,31,32}$ Second, thermodynamic properties of N-compounds in PBI polymer may have influenced functional nanofibre surface area. ${ }^{27,28}$

\subsection{Theoretical Studies}

HOMO-LUMO gap which predicts reactivity between molecules by providing the electronic properties was studied. Adducts formed between PBI and carbazole indicated that the HOMO is centred on PBI while LUMO is shared between PBI and carbazole (Fig. 6). This clearly shows that the interaction between PBI nanofibres and carbazole occur through pi-pi stacking. ${ }^{15}$ The mode of interaction between PBI with quinoline and pyrimidine were similar. Both interactions showed that the HOMO and LUMO positions centred on the PBI with a clear indication of hydrogen bonding formation (Figs. 7 \& 8). Molecular interactions between the various nitrogen-containing 
$<$ https://journals.sabinet.co.za/content/journal/chem/>.
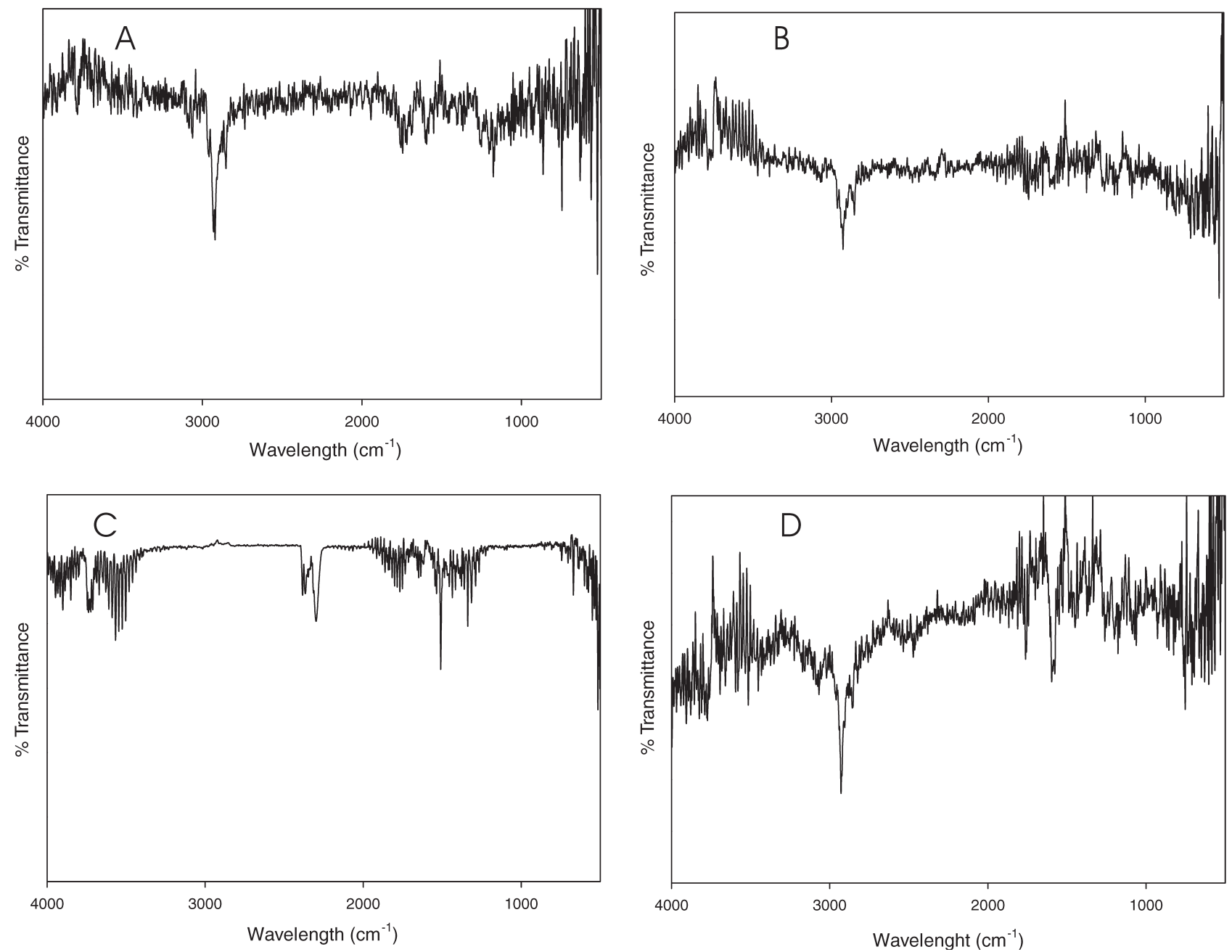

Figure 3 FTIR spectra of gases evolved during TGA analysis of pristine nanofibres (P-PBI) (A), pyrimidine-based PBI nanofibres (PYM-PBI) (B), quinoline-based nanofibres (QUN-PBI) (C) and carbazole-based nanofibres (CAR-PBI) (D).
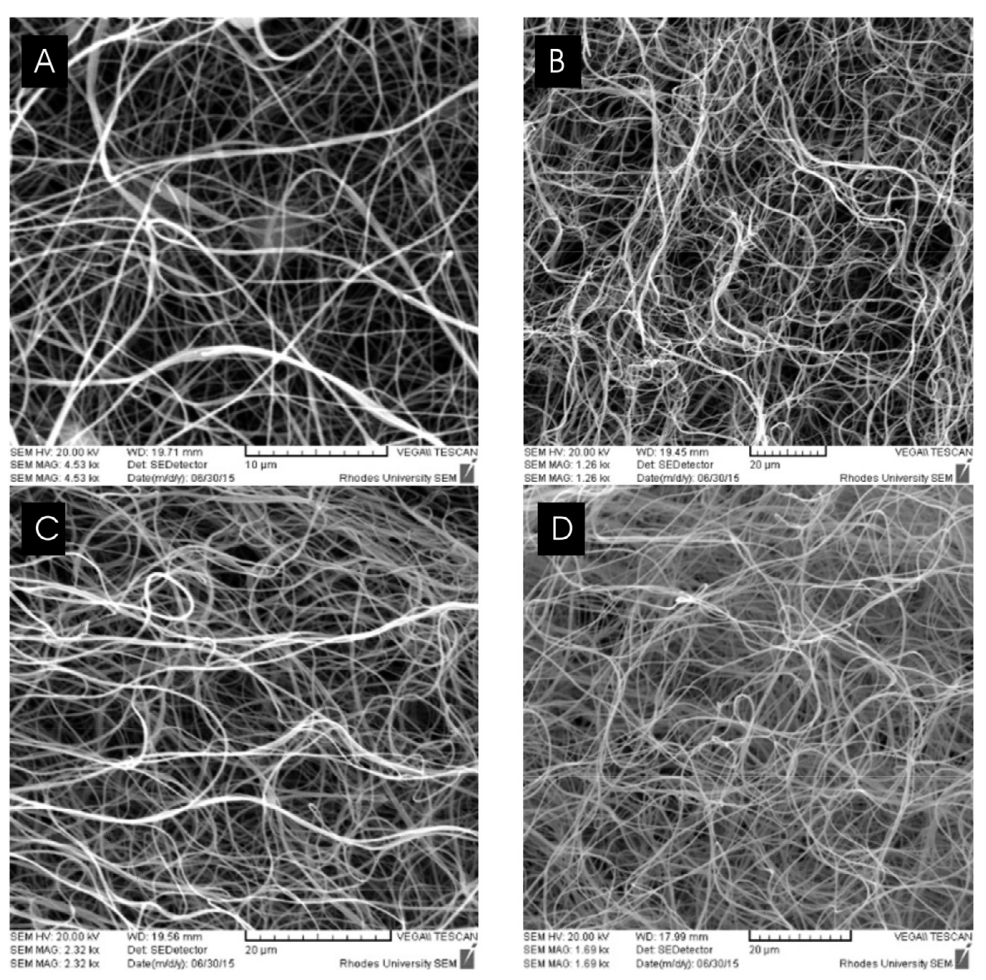

Figure 4 Scanning electron micrograph (SEM) images of (A) pristine nanofibres (P-PBI), (B) carbazole-based nanofibres (CAR-PBI), (C) quinolinebased nanofibres (QUN-PBI) and (D) pyrimidine-based PBI nanofibres (PYM-PBI). 
<https://journals.sabinet.co.za/content/journal/chem/>.
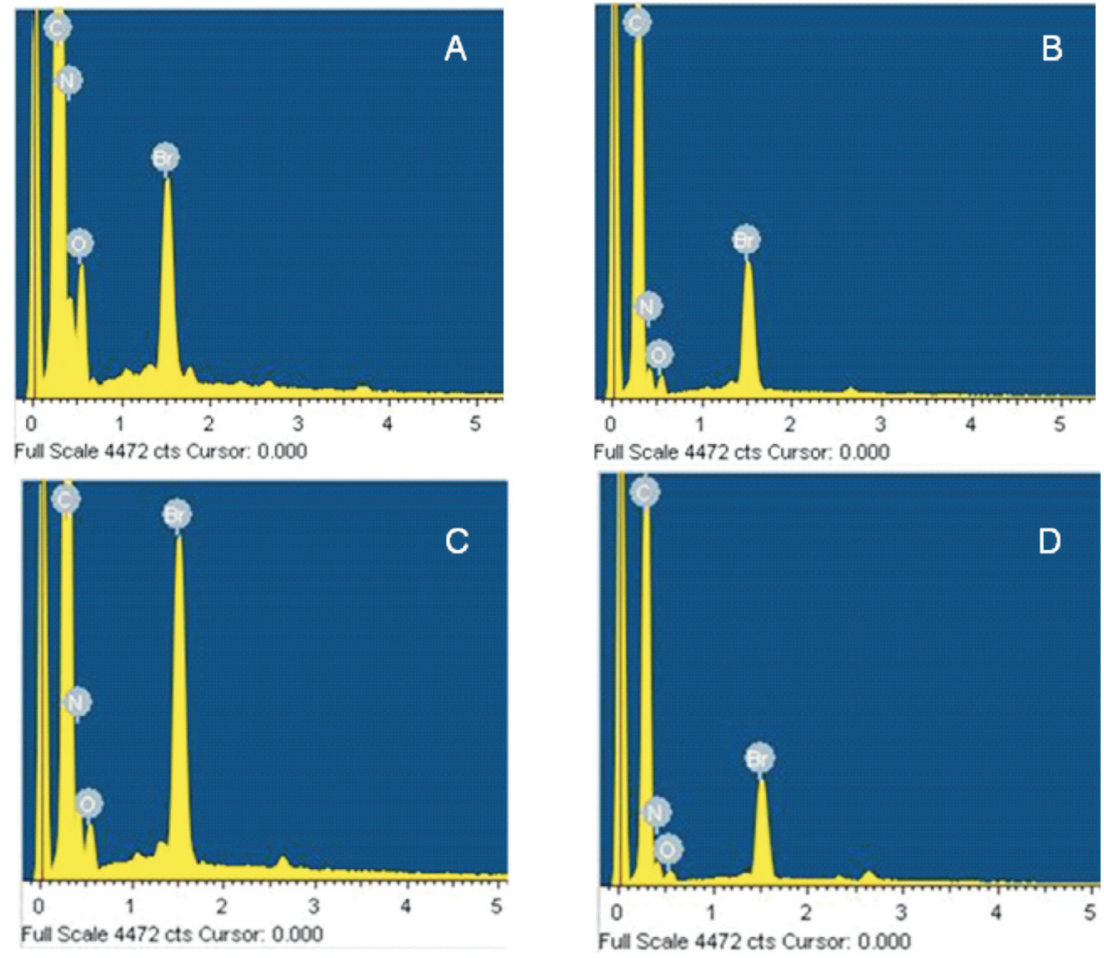

Figure 5 Energy Dispersive Spectroscopy (EDX) of (A) pristine PBI nanofibres, (B) pyrimidine-based PBI nanofibres, (C) quinoline-based PBI nanofibres, and (D) carbazole-based PBI nanofibres

Table 1 Surface area and pore volumes of nanofibres

\begin{tabular}{ccc}
\hline Adsorbents (nanofibres) & Surface area $/ \mathrm{m}^{2} \mathrm{~g}^{-1}$ & Pore size $/ \AA$ \\
\hline P-PBI & $88.0 \pm 26.0$ & $49 \pm 10$ \\
QUN-PBI & $28.1 \pm 3.7$ & $48 \pm 6$ \\
CAR-PBI & $35.1 \pm 2.0$ & $52 \pm 4$ \\
PYM-PBI & $25.1 \pm 3.1$ & $51 \pm 7$ \\
\hline
\end{tabular}

Pristine nanofibres (P-PBI), carbazole-based nanofibres (CAR-PBI), quinolinebased nanofibres (QUN-PBI) and pyrimidine-based PBI nanofibres (PYM-PBI).

compounds with PBI resulted in a decrease in HOMO-LUMO energy gap when compared to the HOMO-LUMO gap of the nitrogen compounds. Polybenzimidazole-carbazole adduct (PBI-CAR), polybenzimidazole-pyrimidine adduct (PBI-PYM) and polybenzimidazole-quinoline adduct (PBI-QUN) all gave lower HOMO-LUMO gap as compared to the values obtained for carbazole (CAR), pyrimidine (PYM), quinoline (QUN) and polybenzimidazole (PBI) (Table 2), further signifying interactions between the various $\mathrm{N}$ - compounds and PBI.

The order of nitrogen-containing compounds hardness and softness is quinoline $(\mathrm{QUN})<$ pyrimidine $(\mathrm{PYM})<$ carbazole (CAR), thus indicating that quinoline interacts the most and carbazole is least. Electronegativity data agree with the

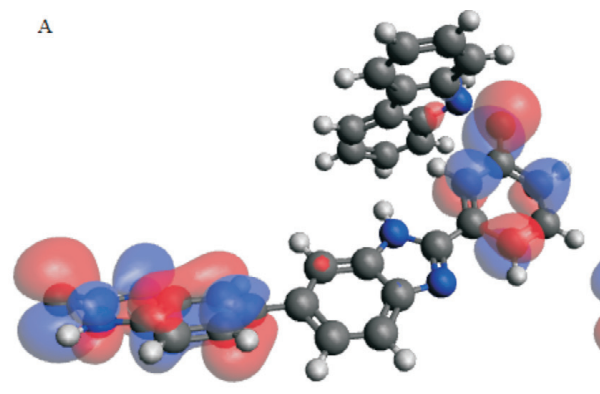

HOMO-LUMO diagram which indicates that electrons are donated by PBI polymer. Some electronic structure identifiers of the studied adducts are presented in Table 2.

Thermodynamic parameters such as enthalpy $(\Delta \Delta \mathrm{H})$, entropy $(\Delta \Delta S)$ and free energies $(\Delta \Delta G)$ resulting from adduct formation are presented in Table 3. A decrease in the order of adsorption spontaneity based on Gibb's free and enthalpy is in the order of pyrimidine $>$ quinoline $>$ carbazole. Negative enthalpy $\left(\Delta \mathrm{H}_{\mathrm{b}}\right)$ value resulting from interaction molecules contributed to an exothermic

\subsection{Adsorption Studies}

\subsubsection{Selectivity Studies}

Adsorption capacities observed when functional PBI nanofibres were employed under mechanical agitation at $150 \mathrm{rpm}$ for target $\mathrm{N}$-compounds revealed that quinoline-based functional PBI nanofibres (QUN-PBI) gave $11.4 \pm 0.9 \mathrm{mg} \mathrm{g}^{-1}$, quinoline (Fig. S2), pyrimidine-based PBI nanofibres (PYM-PBI) gave $11.8 \pm 0.6 \mathrm{mg} \mathrm{g}^{-1}$, pyrimidine (Fig. S3) and carbazole-based PBI nanofibres (CAR-PBI) gave $11.1 \pm 1.2 \mathrm{mg} \mathrm{g}^{-1}$, carbazole (Fig. S4). The pristine PBI nanofibres presented a non-specific binding. ${ }^{15}$ Though naphthalene may be more compatible with the aromatic groups of PBI employed, hence, potentially favouring its

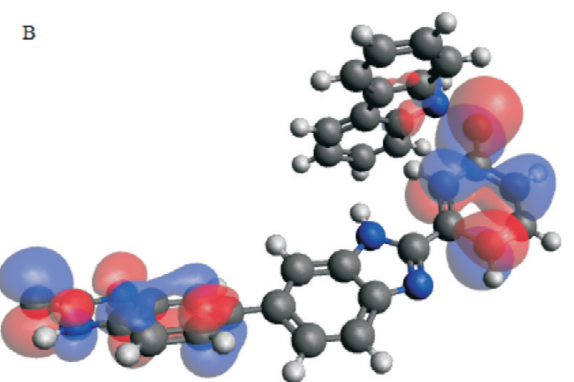

Figure 6 (A) HOMO and (B) LUMO positions of polybenzimidazole unit vs carbazole (PBI-CAR). 

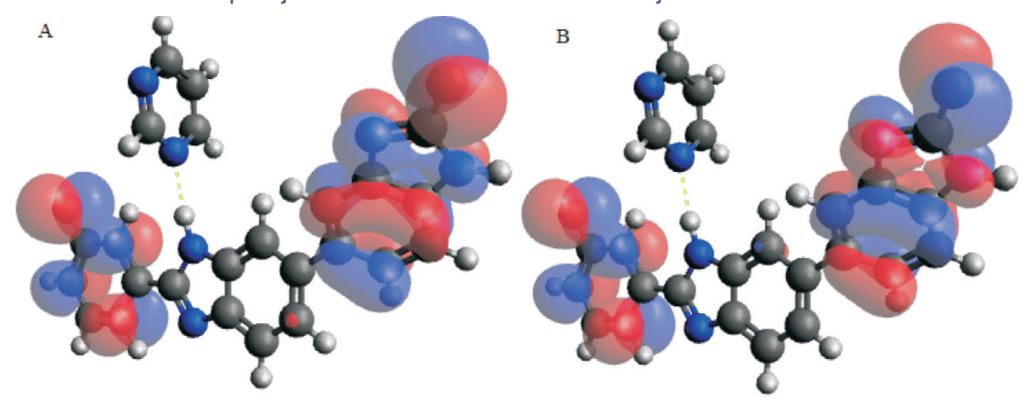

Figure 7 (A) HOMO and (B) LUMO positions of polybenzimidazole unit vs pyrimidine (PBI-PYM).
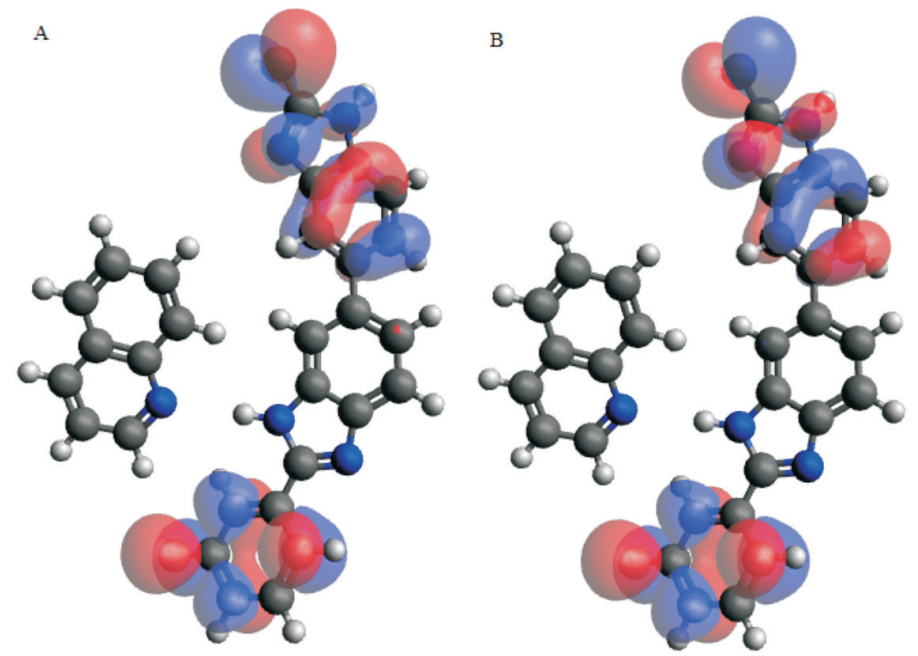

Figure 8 (A) HOMO and (B) LUMO positions of polybenzimidazole unit and quinoline (PBI-QUN).

Table 2 Quantum chemical parameters and some electronic structure identifiers of the studied adducts.

\begin{tabular}{|c|c|c|c|c|c|c|c|c|}
\hline Compounds & $\begin{array}{l}\mathrm{E}_{\mathrm{H}} \\
\text { /a.u. }\end{array}$ & $\begin{array}{l}E_{L} \\
\text { /a.u. }\end{array}$ & $\begin{array}{l}\text { Orbital Energy } \\
\text { Gap. }\left(\mathrm{E}_{\mathrm{G}}\right) \\
\text { /a.u. }\end{array}$ & $\begin{array}{c}{ }^{\mathrm{a}} \text { Orbital Energy } \\
\text { Gap. }\left(\mathrm{E}_{\mathrm{G}}\right) \\
\text { /eV }\end{array}$ & $\begin{array}{c}\text { Hardness } \\
\qquad / \eta\end{array}$ & $\begin{array}{l}\text { Softness } \\
\qquad / \sigma\end{array}$ & $\begin{array}{l}\text { Electro- } \\
\text { negativity } \\
/ \chi\end{array}$ & $\begin{array}{c}\text { Chemical } \\
\text { potential } \\
/ \mu\end{array}$ \\
\hline Polybenzimidazole (PBI) & -0.15201 & -0.14260 & 0.00941 & 0.25606 & 0.128031 & 7.81061 & 4.00842 & -4.00842 \\
\hline Carbazole (CAR) & -0.20870 & -0.03452 & 0.17418 & 4.73698 & 2.369867 & 0.42196 & 3.30922 & -3.30922 \\
\hline Pyrimidine (PYM) & -0.25482 & 0.04252 & 0.21230 & 5.77698 & 4.045563 & 0.24718 & 2.88852 & -2.88852 \\
\hline Quinoline (QUN) & -0.23116 & -0.05082 & 0.18034 & 4.90730 & 2.453679 & 0.40755 & 3.83658 & -3.83658 \\
\hline PBI-CAR-0.14415 & -0.13444 & 0.00971 & 0.26422 & 0.132113 & 7.56929 & 3.79045 & -3.79045 & \\
\hline PBI-PYM-0.15995 & -0.15031 & 0.00964 & 0.26232 & 0.131160 & 7.62425 & 4.22135 & -4.22135 & \\
\hline PBI-QUN-0.15358 & -0.14416 & 0.00942 & 0.25633 & 0.128167 & 7.80231 & 4.05101 & -4.05101 & \\
\hline
\end{tabular}

a a.u. is converted to $\mathrm{eV}$ by using the conversion factor of 27.2114 .

recognition via additional $\pi-\pi$ stacking interactions around the binding sites. Indeed some level of adsorption took place (see Figs S2-S4), however, cannot be compared with the levels of adsorptions obtained for $\mathrm{N}$-compounds. It was obvious that the print molecule mixed with the functional polymer selected to interact with specific functionality hence guiding the assembly of functional polymer.

In comparison of the functional PBI nanofibres, the different

Table 3 DFT molecular modelling thermodynamic data $(\Delta \Delta \mathrm{H}, \Delta \Delta \mathrm{G}$ and $\Delta \Delta S$ ) on the formation of adduct between nitrogen compounds and polybenzimidazole (PBI).

\begin{tabular}{lccc}
\hline & $\Delta \Delta \mathrm{G} / \mathrm{kJ} \cdot \mathrm{mol}^{-1}$ & $\Delta \Delta \mathrm{H} / \mathrm{kJ} \mathrm{mol}^{-1}$ & $\Delta \Delta \mathrm{S} / \mathrm{kJ} \mathrm{K}^{-1}$ \\
\hline Carbazole & -1.314 & -4.606 & 0.0109 \\
Quinoline & -62.596 & -68.252 & 0.0188 \\
Pyrimidine & -77.028 & -81.374 & 0.0147 \\
\hline
\end{tabular}

gave quite different adsorption selectivity. The adsorption selectivity decreased in the order of pyrimidine $\left(\alpha_{\mathrm{i}-\mathrm{r}}=205.9\right)<$ quinoline $\left(\alpha_{\mathrm{i}-\mathrm{r}}=186.6\right)<$ carbazole $\left(\alpha_{\mathrm{i}-\mathrm{r}}=116.7\right)$. The variable selectivity factor was due to the functional groups and chemical properties around analyte (nitrogen compound) as well as polymer networks' ability to consistently conjugate with targeted molecules, thus giving rise to the observed adsorption selectivity. ${ }^{27}$ Second, there is also a possibility of surface heterogeneity leading to multiple adsorption sites, thus contributing to adsorbent-adsorbate interaction.

\subsubsection{Adsorption Kinetics}

A plot showing the progress of adsorption (adsorption capacities vs time) indicated that $\mathrm{N}$-compounds adsorption was linear for $7 \mathrm{~h}$ due to the availability of adsorption sites and cavities for interactions, then slowed as equilibrium was reached (Fig. S5). Pseudo-first-order and pseudo-second-order models were calculated for better description of the adsorption kinetics. ${ }^{15}$ 


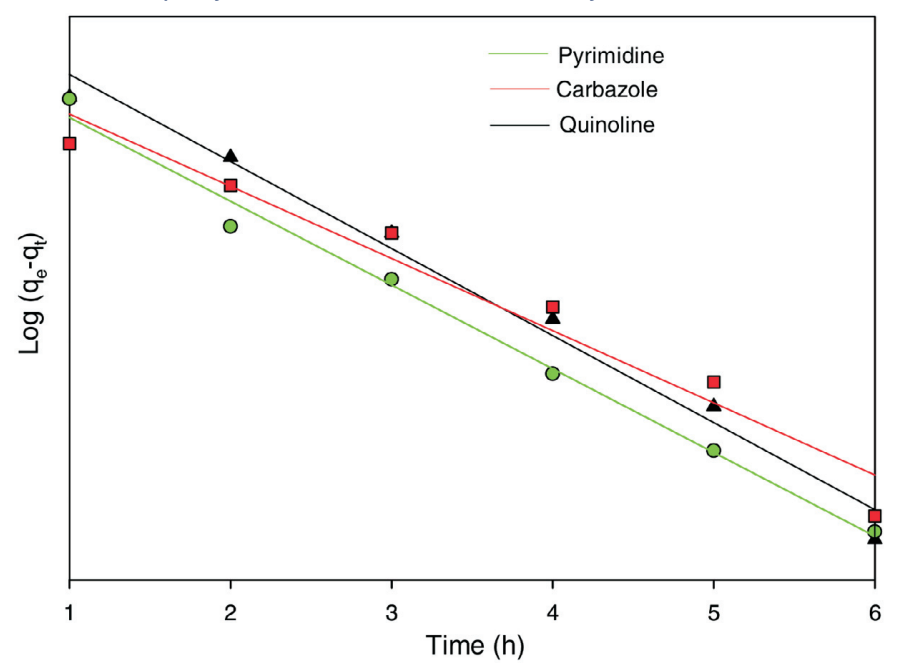

Figure 9 Pseudo-first-order plot of pyrimidine, carbazole and quinoline.

Adsorption kinetics for all model compounds fitted the pseudo-first-order model, based on the obtained regression coefficients $\left(\mathrm{R}^{2}\right)$ (Fig. 9). The pseudo-first-order and pseudosecond-order parameters (regression coefficients) are presented in Table 4. The adsorption kinetics for pseudo-second-order model is available in Fig. S6.

\subsubsection{Adsorption Isotherms}

Adsorption behaviour of nitrogen-containing compounds with functional PBI nanofibres fitted the Freundlich adsorption model (Fig. 10) which indicated the possibility of forming a multi-layered adsorption with functional PBI nanofibres. ${ }^{33}$ The Langmuir plot $\mathrm{C}_{e} / \mathrm{q}_{\mathrm{e}}$ against $\mathrm{C}_{\mathrm{e}}$ (Fig. S7), which describes the probability of chemical adsorption, offered a lower regression which did not fit (Table 5).

Table 4 Kinetic data of pseudo-first-order and pseudo-second-order.

\begin{tabular}{lcccc}
\hline & \multicolumn{2}{c}{$\begin{array}{c}\text { Pseudo-first-order } \\
\text { kinetics }\end{array}$} & \multicolumn{2}{c}{$\begin{array}{c}\text { Pseudo-second-order } \\
\text { kinetics }\end{array}$} \\
& $\mathrm{k} / \mathrm{h}^{-1}$ & $\mathrm{R}^{2}$ & $\mathrm{k}_{2}\left(/ \mathrm{g} \mathrm{mg}^{-1} \mathrm{~h}^{-1}\right) \times 10^{-4}$ & $\mathrm{R}^{2}$ \\
\hline Quinoline & 0.249 & 0.9836 & 1.770000 & 0.4253 \\
Carbazole & 0.295 & 0.9560 & 0.370000 & 0.0999 \\
Pyrimidine & 0.647 & 0.9914 & 0.000119 & 0.1708 \\
\hline
\end{tabular}

\subsubsection{Adsorption Isotherms}

Adsorption behaviour of nitrogen-containing compounds with functional PBI nanofibres fitted the Freundlich adsorption model (Fig. 10) which indicated the possibility of forming a multi-layered adsorption with functional PBI nanofibres..$^{33}$ The Langmuir plot $C_{e} / q_{e}$ against $C_{e}$ (Fig. S7) which describes the probability of chemical adsorption offered a lower regression which did not fit (Table 5).

\subsection{Thermodynamic Parameters}

\subsubsection{Van't Hoff Plots}

Thermodynamic values $\left(\Delta \mathrm{H}^{\circ}, \Delta \mathrm{S}^{\circ}\right.$ and $\left.\Delta \mathrm{G}_{\text {ad }}^{\circ}\right)$ of the various organonitrogen compounds generated from Van't Hoff plots are presented in Fig. 11 and Table 6, respectively. ${ }^{34,35}$ Negative $\Delta G_{\text {ad }}^{\circ}$

Table 5 Parameters of Langmuir adsorption model and Freundlich adsorption model.

\begin{tabular}{lccccccc}
\hline & \multicolumn{4}{c}{ Langmuir parameters } & \multicolumn{3}{c}{ Freundlich parameters } \\
& $\mathrm{Q}_{\mathrm{m}}$ & $\mathrm{K}_{\mathrm{d}}$ & $\mathrm{R}^{2}$ & $\mathrm{n}$ & $\mathrm{K}$ & $\mathrm{R}^{2}$ \\
\hline Quinoline & 90 & 917 & 0.8108 & 0.97 & 1.11 & 0.9873 \\
Carbazole & 1133 & 10956 & 0.7481 & 1.01 & 1.51 & 0.9984 \\
Pyrimidine & 204 & 2036 & 0.4253 & 0.99 & 1.09 & 0.9871 \\
\hline
\end{tabular}

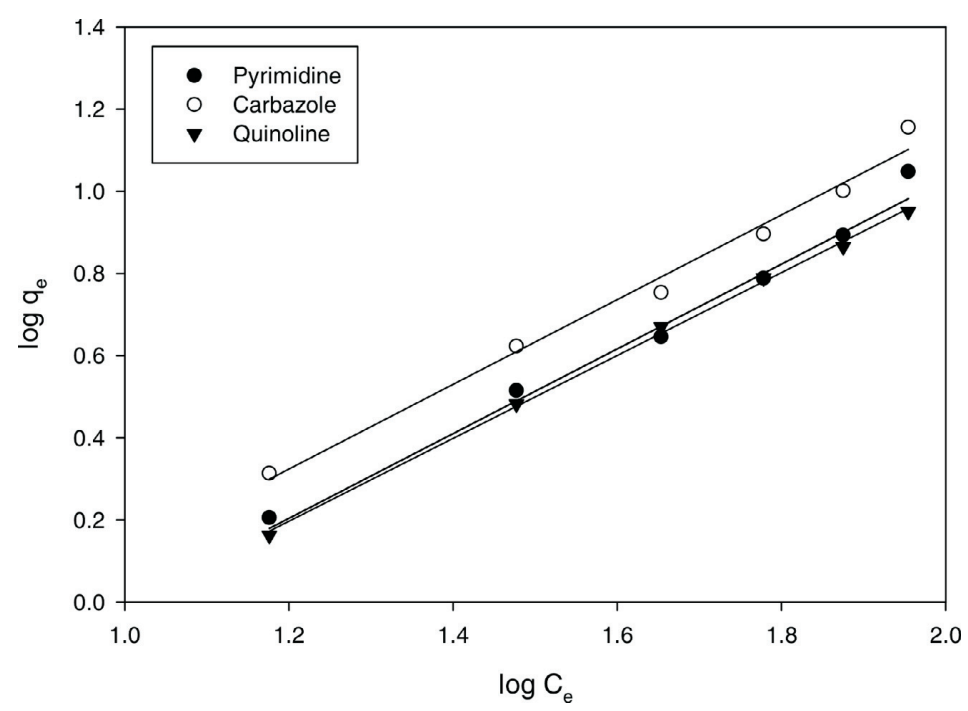

Figure 10 Freundlich plot of carbazole, quinoline and pyrimidine. 
<https://journals.sabinet.co.za/content/journal/chem/>.

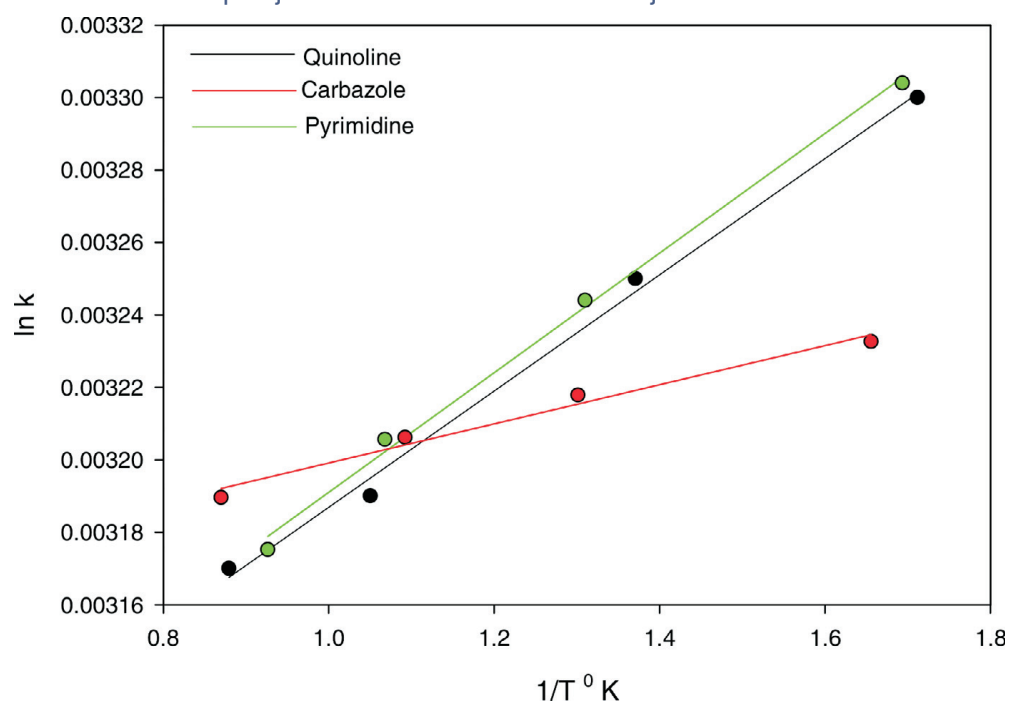

Figure 11 Van't Hoff Plot of adsorption equilibrium constant $K_{a d}$ for adsorption of N-compounds onto functional PBI.

Table 6 Thermodynamic properties obtained from Van't Hoff plot

\begin{tabular}{lccc}
\hline & $\begin{array}{c}\text { Free energy }\left(\Delta \mathrm{G}_{\mathrm{ad}}\right) \\
/ \mathrm{kJ} \mathrm{mol}^{-1}\end{array}$ & $\begin{array}{c}\text { Enthalpy }\left(\Delta \mathrm{H}_{\mathrm{ad}}\right) \\
/ \mathrm{kJ} \mathrm{mol}^{-1} \times 10^{-4}\end{array}$ & $\begin{array}{c}\text { Entropy }\left(\Delta \mathrm{S}_{\mathrm{ad}}\right) \\
/ \mathrm{kJ} \mathrm{K}^{-1}\end{array}$ \\
\hline PBI-Quinoline & -61.7 & -16.6 & 0.207 \\
PBI-Pyrimidine & -275.3 & -7.8 & 0.924 \\
PBI-Carbazole & -63.8 & -4.6 & 0.214 \\
\hline
\end{tabular}

Temperature $=298 \mathrm{~K}$

observed for all plots indicated that the adsorption process is significant. However, a much higher $\Delta \mathrm{G}_{\mathrm{ad}}^{\circ}$ values were obtained for pyrimidine indicating a greater degree of freedom and spontaneity than quinoline and carbazole sorption.

The negative $\Delta \mathrm{H}^{\circ}$ values confirmed the exothermic nature of the adsorption process. The positive value of $\Delta \mathrm{S}^{\circ}$ obtained for $\mathrm{N}$-compounds vs PBI suggests increased randomness at the solid/solution interface, therefore influencing the affinity of functional PBI nanofibres toward the various N-compounds. ${ }^{36}$

\subsubsection{Isothermal Titration Calorimetry (ITC)}

Binding thermodynamic studies between nitrogen compounds ((A) quinoline, (B) pyrimidine and (C) carbazole) with polybenzimidazole (PBI) was followed experimentally by using the isothermal titration calorimetry (ITC) (Fig. 12). ${ }^{35}$

Negative Gibb's free energies observed in all interactions (quinoline-PBI, pyrimidine-PBI and carbazole-PBI), indicate exothermic processes (Table 7). Based on the obtained enthalpy $\left(\Delta \mathrm{H}_{\mathrm{b}}\right)$ values, pyrimidine-PBI offers a better interaction as compared to quinoline-PBI and carbazole-PBI (Table 7). The enhanced interaction observed PBI-pyrimidine interaction is attributed to rich electron density offered by the molecule, thus offering various forms of interactions such as $\mathrm{H}$-bonding and pi-pi interactions. Stoichiometry of interaction (n), binding constant $(K)$, free energy $\left(\Delta \mathrm{G}_{\mathrm{b}}\right)$, enthalpy $\left(\Delta \mathrm{H}_{\mathrm{b}}\right)$ and entropy $\left(\Delta \mathrm{S}_{\mathrm{b}}\right)$ is presented in Table 7.

\subsection{Reusability Studies}

Adsorption capacities of functional PBI nanofibres decreased slightly for all nitrogen compounds upon reusing for three cycles (Table 8). A measurement of various fibre diameter range shows no increase in sizes which may occur during polymer swelling (quinoline-based PBI nanofibres $(2.20-2.60 \mu \mathrm{m})$, pyrimidine-based PBI nanofibres (1.60-3.20 $\mu \mathrm{m})$ and carbazole-based PBI nanofibres $(1.40-2.30 \mu \mathrm{m}))$. Functional PBI nanofibres retained their morphology after use (three cycles) as adsorbents (Fig. 13). Adsorbents were regenerated by washing nanofibres with a mixture of warm methanol and acetonitrile (1:1) after each cycle. A slight drop in adsorption capacities was not attributed nanofibre recognition integrity based on the observed SEM images, but rather a decrease in available functional groups, especially $-\mathrm{NH}$ responsible for interaction (adsorption). ${ }^{36}$

\subsection{Adsorption Studies in Diesel Fuel}

Hydro-treated diesel was denitrogenated by using SPE technique under vacuum. ${ }^{37}$ Initial analysis of the diesel via the use of LECO Pegasus 4D GCxGC-TOFMS showed that organonitrogen compounds were present in diesel (Fig. 14).

Functional PBI nanofibres show promise in the adsorption of refractory organonitrogen compounds (Fig. 14) as observed organonitrogen compounds peak area reduced after adsorption studies (Table 9).

However, the adsorbent presented two complexities; (i) adsorption of some aliphatic and aromatic compounds, and (ii) adsorption of pristine nitrogen-containing compounds (Table 9). The identified molecules could easily interact with PBI via hydrogen bonding and $\pi-\pi$ interactions. 3-( $N, N$-dimethylamino)-9-methylcarbazole, a highly alkylated compound could not be eliminated completely due to the alkyl groups surrounding the compound, thus inhibiting interactions (Table 9).

To further confirm material selectivity properties in real fuel further tests was done. A mixture composed of pyrimidine (120 $\left.\mathrm{mg} \mathrm{L}^{-1}\right)$, quinoline $\left(120 \mathrm{mg} \mathrm{L}^{-1}\right)$ and carbazole $\left(120 \mathrm{mg} \mathrm{L}^{-1}\right)$

Table 7 Thermodynamic properties obtained from Isothermal titration calorimetry (ITC).

\begin{tabular}{lccccc}
\hline & $\begin{array}{c}\text { Free energy }\left(\Delta \mathrm{G}_{\mathrm{b}}\right) \\
/ \mathrm{kJ} \mathrm{mol}^{-1}\end{array}$ & $\begin{array}{c}\text { Stoichiometry of } \\
\text { the interaction } / \mathrm{n}\end{array}$ & $\begin{array}{c}\text { Enthalpy }\left(\Delta \mathrm{H}_{\mathrm{b}}\right) \\
/ \mathrm{kJ} \mathrm{mol}^{-1}\end{array}$ & $\begin{array}{c}\text { Entropy }\left(\Delta \mathrm{S}_{\mathrm{b}}\right) \\
/ \mathrm{kJ} \mathrm{mol}^{-1}\end{array}$ & $\mathrm{k}$ \\
\hline PBI-Quinoline & -26.8 & $9.87 \times 10^{-1}$ & -9.5 & -1.2 & $5.0 \times 10^{4}$ \\
PBI-Pyrimidine & -100.9 & $1.23 \times 10^{1}$ & -14.1 & -0.3 & $8.4 \times 10^{2}$ \\
PBI-Carbazole & -2.1 & $1.35 \times 10^{0}$ & -1.6 & -1.9 & 298 \\
\hline
\end{tabular}


S. Afr. J. Chem., 2019, 72, 88-100,

<https://journals.sabinet.co.za/content/journal/chem/>.
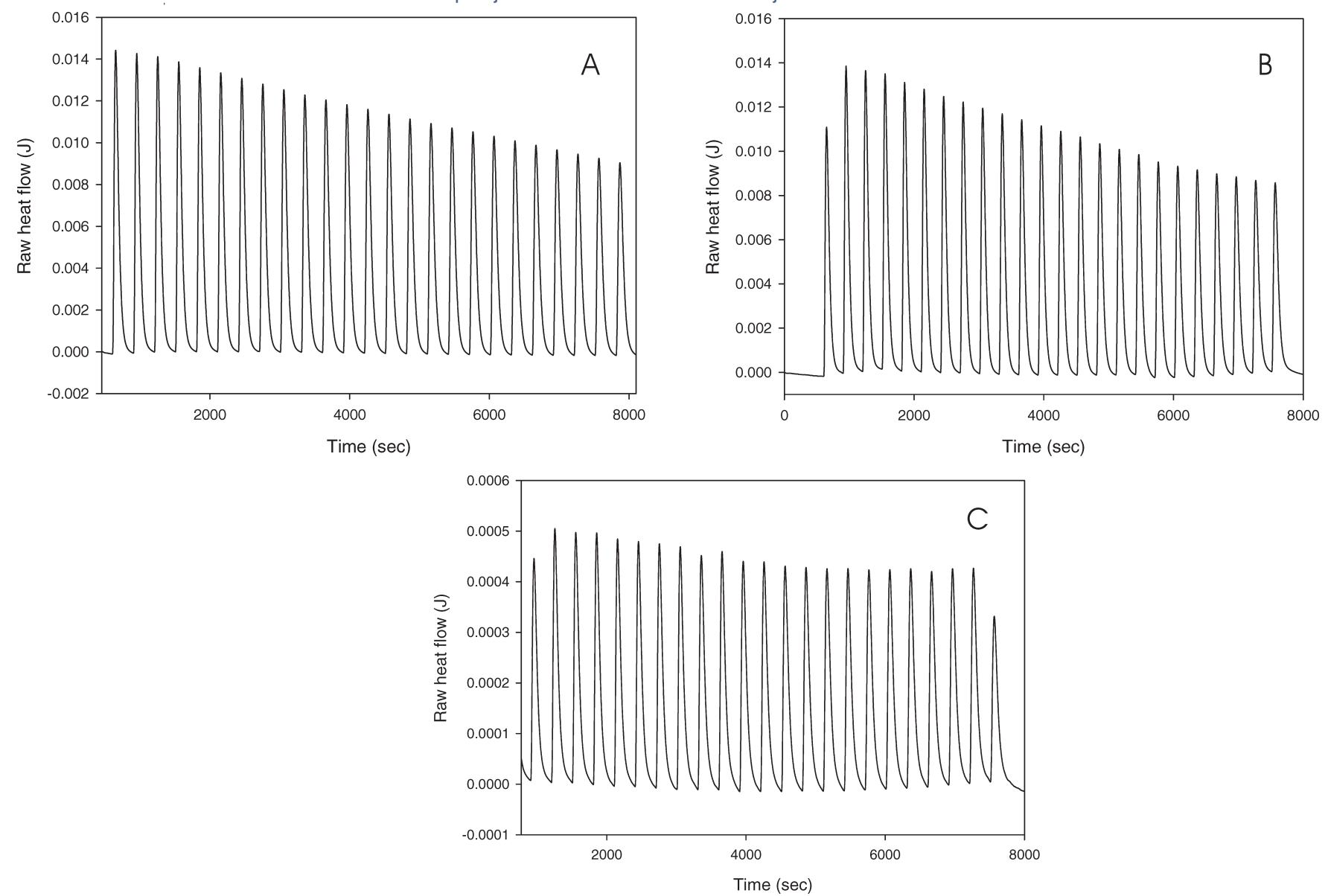

Figure 12 Isothermal titration calorimetric plots of nitrogen compounds ((A) quinoline, (B) pyrimidine and (C) carbazole with polybenzimidazole (PBI).

Table 8 Various amounts of N-compounds absorbed after each cycle.

\begin{tabular}{cccc}
\hline & First adsorption cycle $/ \mathrm{mg} \mathrm{g}^{-1}$ & Second adsorption cycle $/ \mathrm{mg} \mathrm{g}^{-1}$ & ${\text { Third adsorption cycle } / \mathrm{mg} \mathrm{g}^{-1}}$ \\
\hline Carbazole & 11.78 & 10.76 & 10.69 \\
Quinoline & 11.59 & 10.63 & 10.44 \\
Pyrimidine & 11.93 & 11.18 & 10.97 \\
\hline
\end{tabular}

NB: Initial concentration $=120 \mathrm{mg} \mathrm{L}^{-1}$.

was prepared and spiked into real diesel (Fig. 15). Then MIPs mixture (QUN-PBI, CAR-PBI and PYM-PBI) was added to the fuel mixture. A reduction in the concentrations (peak areas) of pyrimidine, quinoline and carbazole was observed after adsorption equilibrium was reached (Fig. 15). The chromatogram below revealed peak area reduction of target organonitrogen
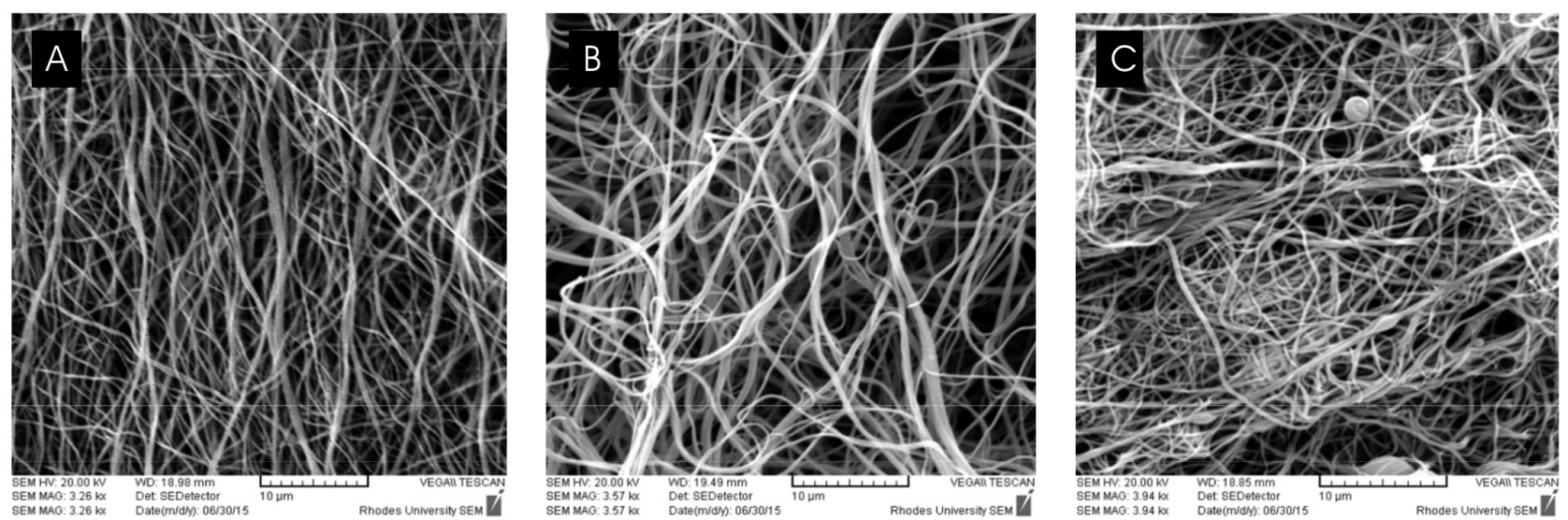

Figure 13 Scanning electron micrograph (SEM) images of (A) quinoline-based PBI nanofibres (QUN-PBI), (B) pyrimidine-based PBI nanofibres (PYM-PBI) and (C) carbazole-based PBI nanofibres (CAR-PBI) after three cycles confirming the polymer integrity was maintained. 
<https://journals.sabinet.co.za/content/journal/chem/>.
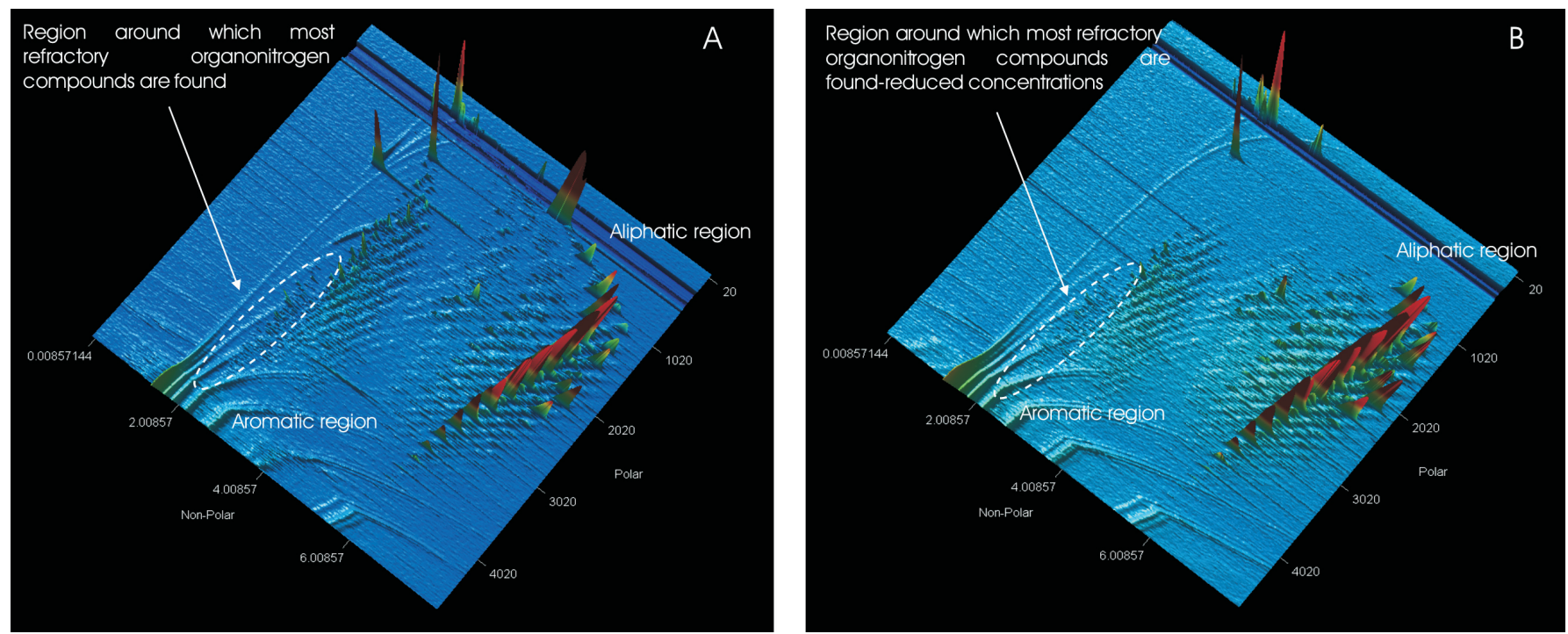

Figure 14 GCxGC-high-resolution TOF-MS surface plot showing (A) the presence of alkylated organonitrogen compounds with surface contour plot (XIC) and (B) the reduction or elimination of alkylated organonitrogen compounds with surface contour plot (XIC) in diesel fuel.

Table 9 Some alkylated organonitrogen compounds found before and after the adsorption of hydrotreated fuel.

\begin{tabular}{|c|c|c|c|c|c|}
\hline Name & Formula & R.T. /s & Base mass & $\begin{array}{c}\text { Area } \\
\text { (before adsorption) }\end{array}$ & $\begin{array}{c}\text { Area } \\
\text { (after adsorption) }\end{array}$ \\
\hline Cumidine & $\mathrm{C}_{9} \mathrm{H}_{13} \mathrm{~N}$ & $1723.39,3.35143$ & 120,0932 & 4676 & ND \\
\hline 1-phenyl-1-propanamine & $\mathrm{C}_{9} \mathrm{H}_{13} \mathrm{~N}$ & $1915.33,3.32572$ & 106,0777 & 95933 & ND \\
\hline 4-Pentyloxyaniline & $\mathrm{C}_{11} \mathrm{H}_{17} \mathrm{NO}$ & $2930.96,5.05715$ & 109,1012 & 47285 & ND \\
\hline 1-Methyl-2,5-dipropyldecahydroquinoline & $\mathrm{C}_{16} \mathrm{H}_{31} \mathrm{~N}$ & $4002.58,2.34857$ & 194,1088 & 7818 & ND \\
\hline 3-(N,N-Dimethylamino)-9-methylcarbazole & $\mathrm{C}_{15} \mathrm{H}_{16} \mathrm{~N}_{2}$ & $4002.58,2.48982$ & 224,1195 & 42756 & 10872 \\
\hline 9H-Carbazol-3-amine, 9-ethyl- & $\mathrm{C}_{14} \mathrm{H}_{14} \mathrm{~N}_{2}$ & $3954.60,2.50286$ & 210,1401 & 30379 & ND \\
\hline 2-Butyl-1-pyrroline & $\mathrm{C}_{8} \mathrm{H}_{15} \mathrm{~N}$ & $3478.83,2.91429$ & 83,0855 & 25596 & ND \\
\hline
\end{tabular}

compounds with selectivity of $96.2 \%, 98.1 \%$ and $92.7 \%$ for pyrimidine, carbazole and quinoline, respectively (Fig. 15). This corresponds to $11.5 \mathrm{mg} \mathrm{g}^{-1}, 11.8 \mathrm{mg} \mathrm{g}^{-1}$ and $11.0 \mathrm{mg} \mathrm{g}^{-1}$, for pyrimidine, carbazole and quinoline, respectively.

The application of functional PBI nanofibres as adsorbent for adsorptive denitrogenation show great potential for the fuel industry. The optimization of adsorption process in the present study has resulted in improved adsorption capacities much higher than those reported in our previous study. ${ }^{38}$ PBI nanofibres gave slow kinetics reaching equilibrium at $480 \mathrm{~min}$, this was probably due to surface area and porosity of functional nanofibres. However, our functional polymer compared well with the reported indole MIPs when selectively was considered (Table 8). ${ }^{18}$ Nonetheless some complications resulting from the

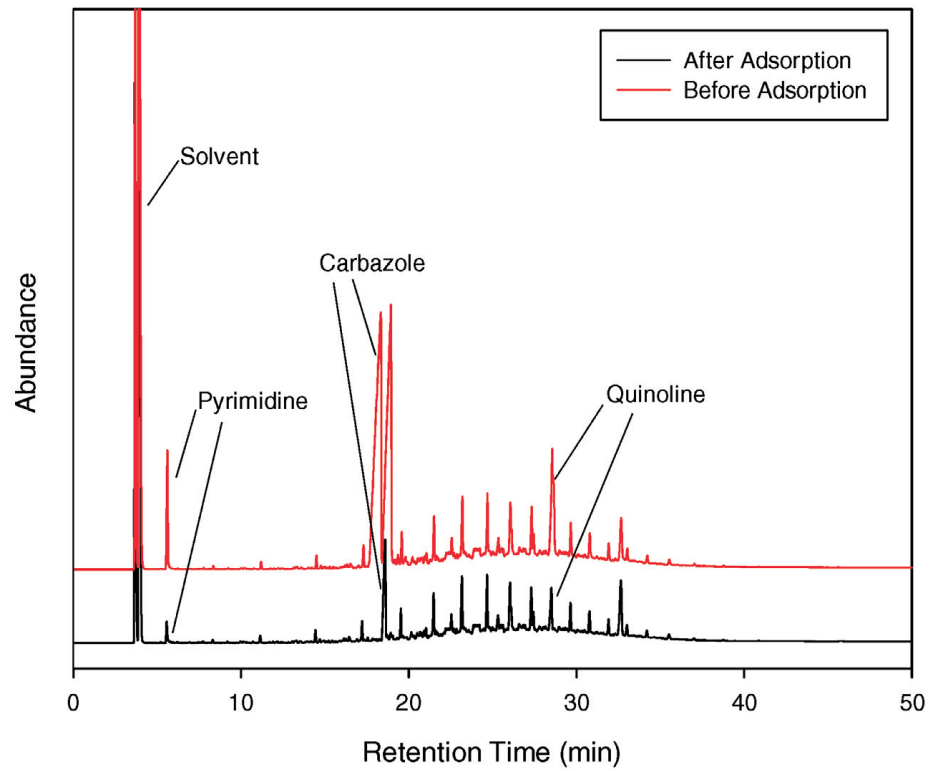

Figure 15 GC-FID chromatograms of diesel fuel containing target nitrogen-containing compounds before and after adsorption. 
ability of the functional PBI polymer to adsorb other compounds, such as cumidine, 1-phenyl-1-propanamine and 4-pentyloxyaniline were reported (Table 8). These was attributed to the ability of the absorbent to easily interact with these compounds via hydrogen bonding. Likewise, solid sorbents such as MOFs employed for fuel denitrogenation..$^{37,39,41-44}$ The design MIPs with high surface area and specific cavities for target analytes would be the foundation for improved organonitrogen selectivity and adsorption capacities.

\section{Conclusion}

Functional polybenzimidazole (PBI) enhanced the adsorption capacities and selectivity of target organonitrogen compounds due to its ability to self-assemble with smaller molecules such as quinoline, carbazole and pyrimidine and also equivalently conjugate with these targeted molecules in the presence of other compounds, thus leading to a remarkable adsorption capacity. Freundlich isotherm confirming multilayer adsorption process was observed for all adsorption. Thermodynamic parameters obtained from Van't Hoff plot indicated negative $\Delta \mathrm{H}^{\circ}$ and $\Delta \mathrm{G}$ values for all $\mathrm{N}$-compounds, thus confirming an exothermic adsorption process, and the data are well correlated with the adsorption capacities rather than physical properties such as surface area and pore sizes. SEM images (diameter measurements) of functional PBI indicate that swelling did not occur on the material even after three adsorption cycles. Density functional theory (DFT) theoretically confirmed the possibility of $\pi-\pi$ interactions and hydrogen bond interactions between $\mathrm{N}$-compounds and functional PBIs. A lone pair nitrogen atom of $\mathrm{N}$-compounds (quinoline and pyrimidine) and the - $\mathrm{NH}$ group of a PBI are responsible for hydrogen bonding. Further improvements are still required in order to achieve the desired adsorption capacities and selectivity through the designing of smart functional materials.

\section{Acknowledgements}

We highly acknowledge financial support to the project in the form of research grant from South African National Research Foundation (NRF Thuthuka) and Sasol (Pty) Ltd. We also acknowledge the Centre for High Performance Computing (CHPC), Cape Town, South Africa, for providing the platform in carrying out the molecular modelling studies on the Gaussian09 software.

\section{Supplementary Material}

Supplementary information is provided in the online supplement.

\section{References}

1 J.W. Bauserman, G.W. Mushrush and D.R. Hardy, Organic nitrogen compounds and fuel instability in middle distillate fuels, Ind. Eng. Chem. Res., 2008, 47, 2867-2875.

2 M. Almari, X. Ma and C. Song, Role of surface oxygen-containing functional groups in liquid-phase adsorption of nitrogen compounds on carbon-based adsorbents, Energy Fuel, 2009, 23, 3940-3947.

3 P.L. Jokuty and M.R. Gray, Resistant nitrogen compounds in hydrotreated gas oil from Athabasca bitumen, Energy Fuel, 1991, 5, 791-795.

4 M. Dorbon and C. Bernasconi, Nitrogen compounds in light cycle oils: identification and consequences of ageing, Fuel, 1989, 68, 1067-1086.

5 G.R. Hartung and D.M. Jewell, Carbazoles, phenazines and dibenzofuran in petroleum products, methods of isolation, separation and determination, Anal. Chim. Acta, 1962, 26, 514-547.

6 J.W. Bauserman, K.M. Nguyen and G.W. Mushrush, Nitrogen compound determination and distribution in three source fuels by GC/MS, J. Pet. Sci. Technol., 2004, 22, 1491-1505.

7 L. Xe, F.R. Alain, P.R. Stephane, X.X. Wang, X. Fu, J. Estager, M. Vrinat and M. Lemaire, Selective extraction and identification of neutral nitrogen compounds contained in straight-run diesel feed using chloride based ionic liquid, Ind. Eng. Chem. Res., 2008, 47, 8801-8807.

8 C.A. Hughey and S.A. Glassow, Detailed compositional comparison of acidic NSO compounds in biodegraded reservoir and surface crude oils by negative ion electrospray Fourier transform ion cyclotron resonance mass spectrometry, Fuel, 2007, (86)56, 758-768.

9 C.N.Satterfield, M. Model, J.F. Mayer, C.N. Satterfield, M. Modell and J.F. Mayer, Interactions between catalytic hydrodesulfurization of thiophene and hydrodenitrogenation of pyridine, AIChE J., 1975, 21, 1100-1197.

10 G.C. Laredo, S. Leyva, R. Alvarez, M.T. Mares, J. Castillo and J.L. Cano, Nitrogen compounds characterization in atmospheric gas oil and light cycle oil from a blend of Mexican crudes, Fuel, 2002, 81, 1341-1350.

11 M.J. Girgis and B.C. Gates, Reactivities, reaction networks, and kinetics in high-pressure catalytic hydroprocessing, Ind. Eng. Chem. Res. 1991, 30, 2021-2058.

12 D. Carnaroglio, E. Gaudino, S. Mantegna, E.M. Moreira, A. Vicente de Castro, E.M.M. Flores and G. Cravotto, Ultrasound-assisted oxidative desulfurization/denitrification of liquid fuels with solid oxidants, Energy Fuel, 2014, 28 (3), 1854-1859.

13 V.C. Srivastava, An evaluation of desulfurization technologies for sulfur removal from liquid fuels, RSC Adv., 2012, 2, 759-783.

14 A.S. Ogunlaja, C. du Sautoy, N. Torto and Z.R. Tshentu, Design, fabrication and evaluation of intelligent sulfone-selective polybenzimidazole nanofibers, Talanta, 2014, 126, 61-72.

15 Y. Cao, L. Liu, W. Xu, X. Wu and W. Huang, Surface molecularly functional polymer prepared by reverse atom transfer radical polymerization for selective adsorption indole, J. Appl. Polym. Sci., 2014, 131, 40473-40483.

16 W. Yang, L. Liu, Z. Zhou, C. Qiu, P. Ma, H. Liu and W. Xu, Rational design and preparation for novel denitrogenation adsorbents by computational simulation and improved atom transfer radical polymerization, New J. Chem., 2013, 37, 2758-2767.

17 B. Mudabuka, A.S. Ogunlaja, Z. R. Tshentu and N. Torto, Electrospun poly(vinylbenzyl chloride) nanofibres functionalised with tris-(2-2' pyridylimidazole)iron(III): a test strip for detection of ascorbic acid and dopamine, Sens. Actuators, B, 2016, 222, 598-604.

18 A.S. Ogunlaja, E. Hosten and Z.R. Tshentu, The oxidation of dibenzothiophene using oxidovanadium(IV)-containing nanofibres as catalyst, S. Afr. J. Chem., 2015, 68, 172-180.

19 D. Chen, L. Wang, Y. Ma and W. Yang, Super-adsorbent material based on functional polymer particles with a multilevel porous structure, NPG Asia Materials, 2016, 8, e301. https://doi.org/10.1038/am.2016.11710.1038/am.2016.117

20 M.J. Frisch, G.W. Trucks, H.B. Schlegel, G.E. Scuseria, M.A. Robb, J.R. Cheeseman, G. Scalmani, V. Barone, G.A. Petersson, H. Nakatsuji, X. Li, M. Caricato, A.V. Marenich, J. Bloino, B.G. Janesko, R. Gomperts, B. Mennucci, H.P. Hratchian, J.V. Ortiz, A.F. Izmaylov, J.L. Sonnenberg, D. Williams-Young, F. Ding, F. Lipparini, F. Egidi, J. Goings, B. Peng, A. Petrone, T. Henderson, D. Ranasinghe, V.G. Zakrzewski, J. Gao, N. Rega, G. Zheng, W. Liang, M. Hada, M. Ehara, K. Toyota, R. Fukuda, J. Hasegawa, M. Ishida, T. Nakajima, Y. Honda, O. Kitao, H. Nakai, T. Vreven, K. Throssell, J.A. Montgomery, Jr., J.E. Peralta, F. Ogliaro, M.J. Bearpark, J.J. Heyd, E.N. Brothers, K.N. Kudin, V.N. Staroverov, T.A. Keith, R. Kobayashi, J. Normand, K. Raghavachari, A.P. Rendell, J.C. Burant, S.S. Iyengar, J. Tomasi, M. Cossi, J.M. Millam, M. Klene, C. Adamo, R. Cammi, J.W. Ochterski, R.L. Martin, K. Morokuma, O. Farkas, J.B. Foresman and D.J. Fox, Gaussian 16, Revision B.01, Gaussian, Inc., Wallingford CT, 2016.

21 A.C. Tella, S.O. Owalude, S.J. Olatunji, S.O. Oloyede, A.S. Ogunlaja and S.A. Bourne, Synthesis, crystal structure and desulfurization properties of zig-zag 1D coordination polymer of copper(II) containing 4-methoxybenzoic acid ligand, J. Sulfur Chem., 2018. DOI: $10.1080 / 17415993.2018 .1489808$

22 D.H. Lataye, I.M. Mishra and I.D. Mall, Pyridine sorption from aqueous solution by rice husk ash (RHA) and granular activated carbon (GAC): parametric, kinetic, equilibrium and thermodynamic aspects, J. Hazard. Mater., 2008, 154, 858-870.

23 A.N. Zhou, X.L. Ma and C.S. Song, Liquid-phase adsorption of multi-ring thiophenic sulfur compounds on carbon materials with different surface properties, J. Phys. Chem. B, 2006, 110, 4699-4707. 
24 C. He, Y. Long, J. Pan. K. Li and F. Liu, Application of molecularly functional polymers to solid phase extraction of analytes from real samples, J. Biochem. Biophys. Methods, 2007, 70, 133-150.

25 B. Sellergen and K.J. Shea. Chiral ion-exchange chromatography: Correlation between solute retention and a theoretical ion-exchange model using functional polymers J. Chromatogr., 1993, 635, 31-49.

26 M.J. Whitcombe, N. Kirsch and I.A. Nicholls, Molecular imprinting science and technology: a survey of the literature for the years 2004-2011, J. Mol. Recognit., 2014, 27(6), 297-401.

27 M.S. Abdul-quadir, R. Van Der Westhuizen, W. Welthagen, E.E. Ferg, Z.R. Tshentu and A.S. Ogunlaja, Adsorptive denitrogenation of fuel over molecularly imprinted poly-2-(1H-imidazol-2-yl)-4-phenol microspheres, New J. Chem., 2018, 42(15), 13135-13146.

28 P.A.G. Cormack and A.Z. Elorza, Molecularly functional polymers: synthesis and characterisation. J. Chromatogr., B 2004, 804, 173-182.

29 Y.J. Yang, J.Y. Li, Y.R. Liu, J.Y. Zhang, B. Li and X.P. Cai, Optimization of polymerization parameters for the sorption of oseltamivir onto molecularly functional polymers, Anal. Bioanal. Chem., 2011, 400, 3665-3674.

30 E.P. Barrett, L.G. Joyner and P.P. Halenda, The determination of pore volume and area distributions in porous substances. I. Computations from nitrogen isotherms, J. Am. Chem. Soc., 1951, 73, 373-380.

31 P. Li, C. Mu, T. Wang, F. Lei, H. Li, Q. Huang and J. Zhou, Selective adsorption of tetrahydropalmatine by a molecularly functional polymer with functional rosin cross-linker, S. Afr. J. Chem., 2014, 67, 67-70.

32 H.Y. Yuan, X.H. Ma and Z.L. Xu, Pore structure analysis of PFSA $/ \mathrm{SiO}_{2}$ composite catalysts from nitrogen adsorption isotherms, Sci. China Chem., 2011, 54, 257-262.

33 S. Aziziana, S. Erisa and L.D. Wilson, Re-evaluation of the centuryold Langmuir isotherm for modelling adsorption phenomena in solution, Chem. Phys. 2018, 513, 99-104.

34 F. Gritti and G. Guiochon, Adsorption mechanisms and effect of temperature in reversed-phase liquid chromatography. Meaning of the classical Van't Hoff plot in chromatography, Anal. Chem., 2006, 78, 4642-4653.
35 X. Ren, Z. Liu, L. Dong, G. Miao, N. Liao, Z. Li and J. Xiao, Dynamic catalytic adsorptive desulfurization of real diesel over ultra-stable and low-cost silica gel supported $\mathrm{TiO}_{2}$, J. AIChE, 2018, 64, 2146-2159.

36 A.S. Ogunlaja, E. Hosten, R. Betz and Z.R. Tshentu, Selective removal of isoquinoline and quinoline from simulated fuel using 1,1'-binaphthyl-2,2'-diol (BINOL): crystal structure and evaluation of the adduct electronic properties, RSC Adv., 2016, 6, 39024-39038.

37 A. Gelencser, G. Kiss, Z. Krivacsy and Z. Varga-Puchony, A simple method for the determination of capacity factor on solid-phase extraction cartridges, J. Chromatogr. A, 1995, 693, 217-225.

38 A.S. Ogunlaja, M.S. Abdul-quadir, P.E. Kleyi, E.E. Ferg, P. Watts and Z.R. Tshentu, Towards oxidative denitrogenation of fuel oils: vanadium oxide-catalysed oxidation of quinoline and adsorptive removal of quinoline-N-oxide using 2,6-pyridine-polybenzimidazole nanofibers, Arabian J. Chem., 2019, 12, 198-214

39 A.L. Nuzhdin, K.A. Kovalenko, D.N. Dybtsev and G.A. Bukhtiyarova, Removal of nitrogen compounds from liquid hydrocarbon streams by selective sorption on metal-organic framework MIL-101, Mendeleev Commun., 2010, 20, 57-58.

40 M. Maes, M. Trekels, M. Boulhout, S. Schouteden, F. Vermoortele, L. Alaerts, D. Heurtaux, Y.K. Seo, Y.K. Hwang, J.S. Chang, I. Beurroies, R. Denoyel, K. Temst, A. Vantomme, P. Horcajada, C. Serre and D.E. De Vos, Selective removal of N-heterocyclic aromatic contaminants from fuels by Lewis acidic metal-organic frameworks, Angew. Chem. Int. Ed., 2011, 50, 4210-4214.

41 G. Férey and G. Férey, Hybrid porous solids: past, present, future, Chem. Soc. Rev., 2008, 37, 191-214.

42 S. Kitagawa, R. Kitaura and S.I. Noro, Functional porous coordination polymers, Angew. Chem. Int. Ed., 2004, 43, 2334-2375.

43 O.M. Yaghi, M. O'Keeffe, N.M. Ockwig, H.K. Chae, M. Eddaoudi and J. Kim, Reticular synthesis and the design of new materials, Nature 2003, 423, 705-714.

44 N.A. Khan, Z. Hasan and S.H. Jhung, Adsorptive removal of hazardous materials using metal-organic frameworks (MOFs): a review, J. Hazard. Mater., 2013, 244-245, 444-456. 


\section{Supplementary material to:}

M.S. Abdul-quadir, R. van der Westhuizen, W. Welthagen, E.E. Ferg, Z.R. Tshentu and A.S. Ogunlaja,

Selective Removal of Organonitrogen Compounds in Fuel using Functional Polybenzimidazole Nanofibres: A Combined Experimental and Theoretical Study,

S. Afr. J. Chem., 2019, 72, 88-100. 
Selective removal of organonitrogen compounds in fuel using molecularly imprinted polybenzimidazole nanofibers: A combined experimental and theoretical study

M. S. Abdul-quadir ${ }^{I}$, R. van der Westhuizen ${ }^{2}$,W. Welthagen ${ }^{2}$, E. E. Ferg ${ }^{l}$, Z. R. Tshentu ${ }^{l}$ and A. S. Ogunlaja $a^{1, *}$

${ }^{1}$ Department of Chemistry, Nelson Mandela University, P.O. Box 77000, Port Elizabeth 6031, South Africa

${ }^{2}$ Analytical Technology, Sasol Technology (Pty) Limited, PO Box 1, Sasolburg 1947, South Africa

\section{Supplementary Data}
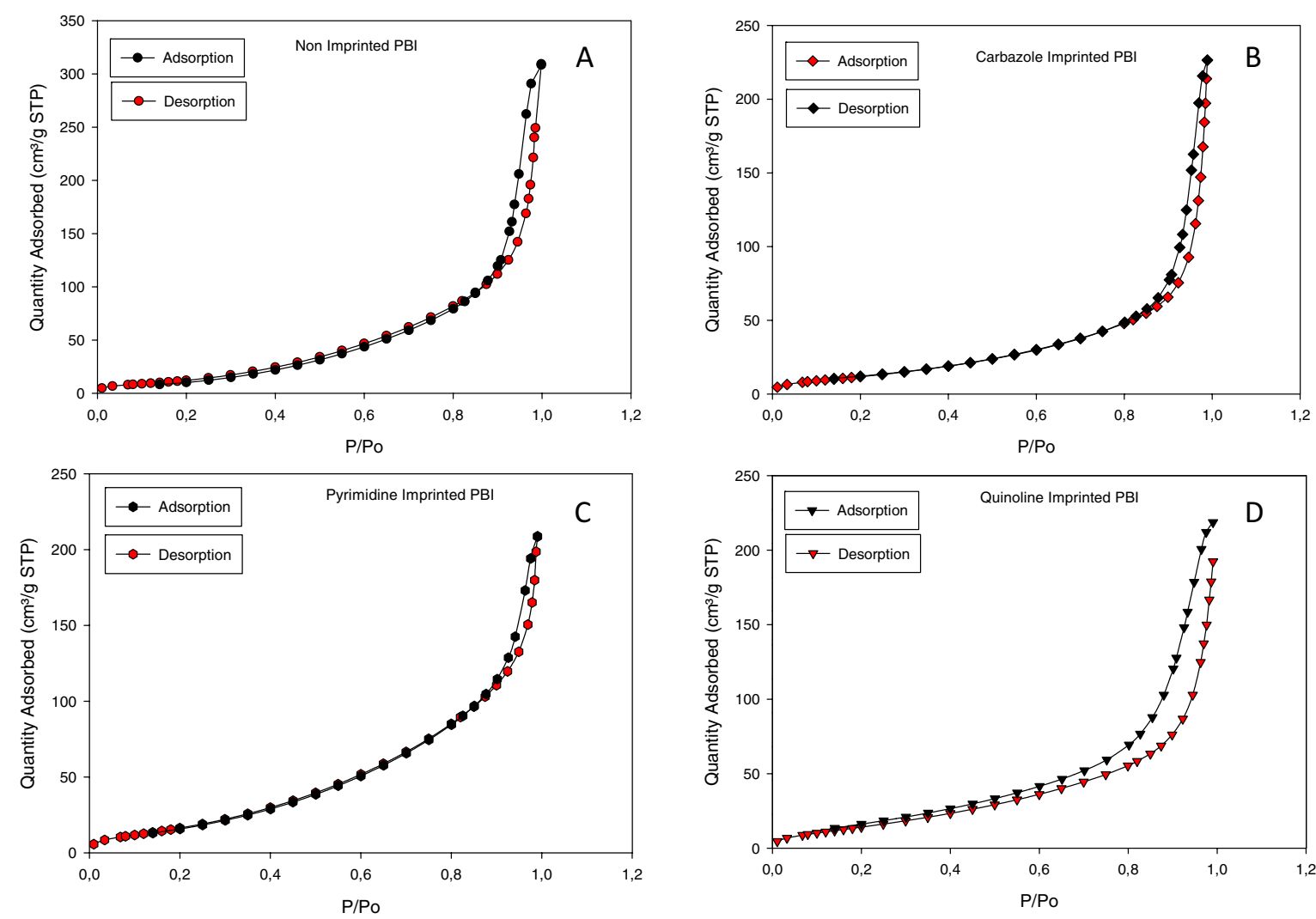

Figure S1. $\mathrm{N}_{2}$ adsorption-desorption isotherms of PBI nanofibers: (A) Non-imprinted nanofibers (NIP-PBI), carbazole imprinted-nanofibers (CAR-PBI), pyrimidine imprinted PBI nanofibers (PYM$\mathrm{PBI})$ and quinoline imprinted nanofibers (QUN-PBI). 


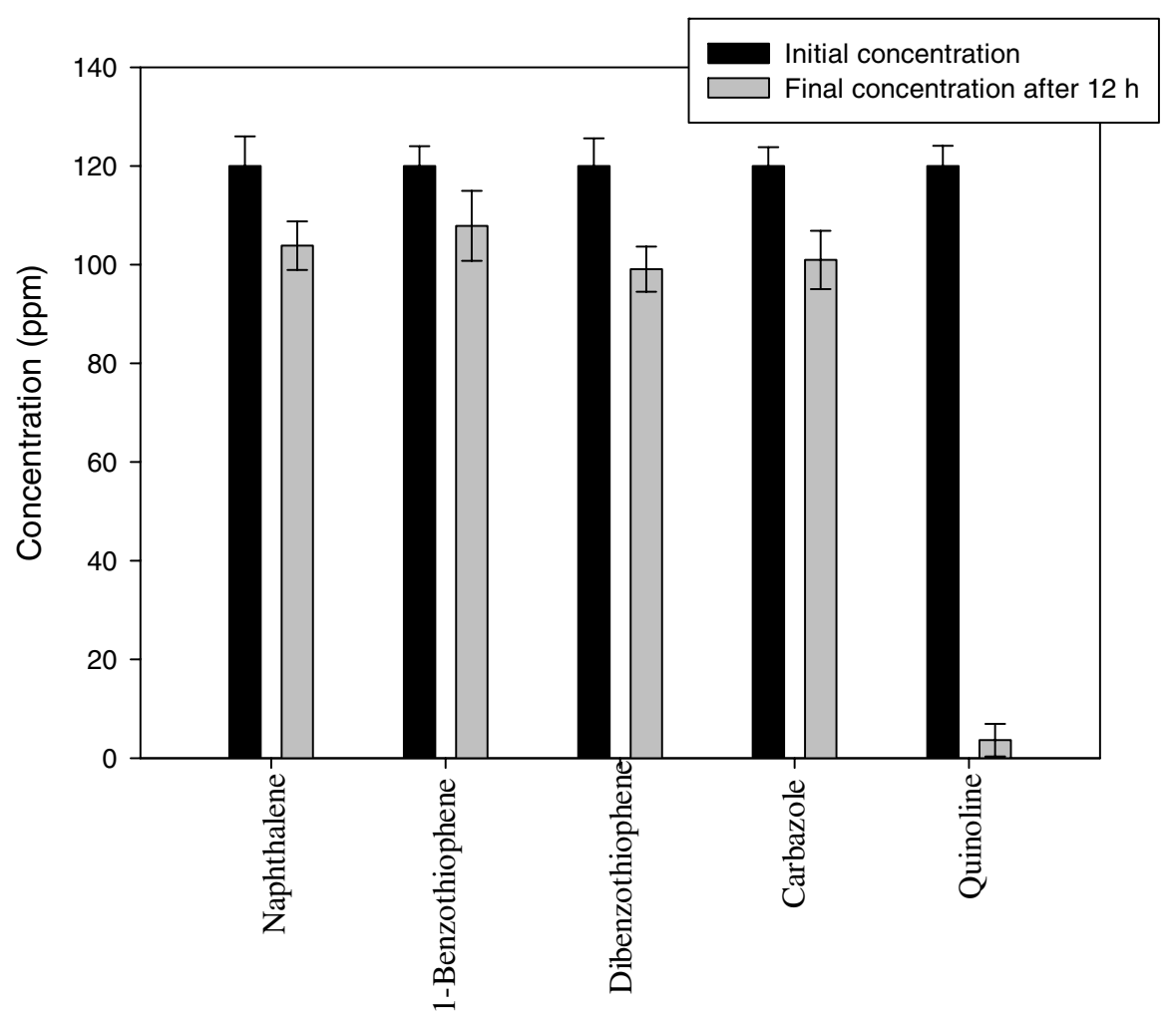

Figure S2. Adsorption selectivity of quinoline using quinoline-imprinted PBI nanofibers.

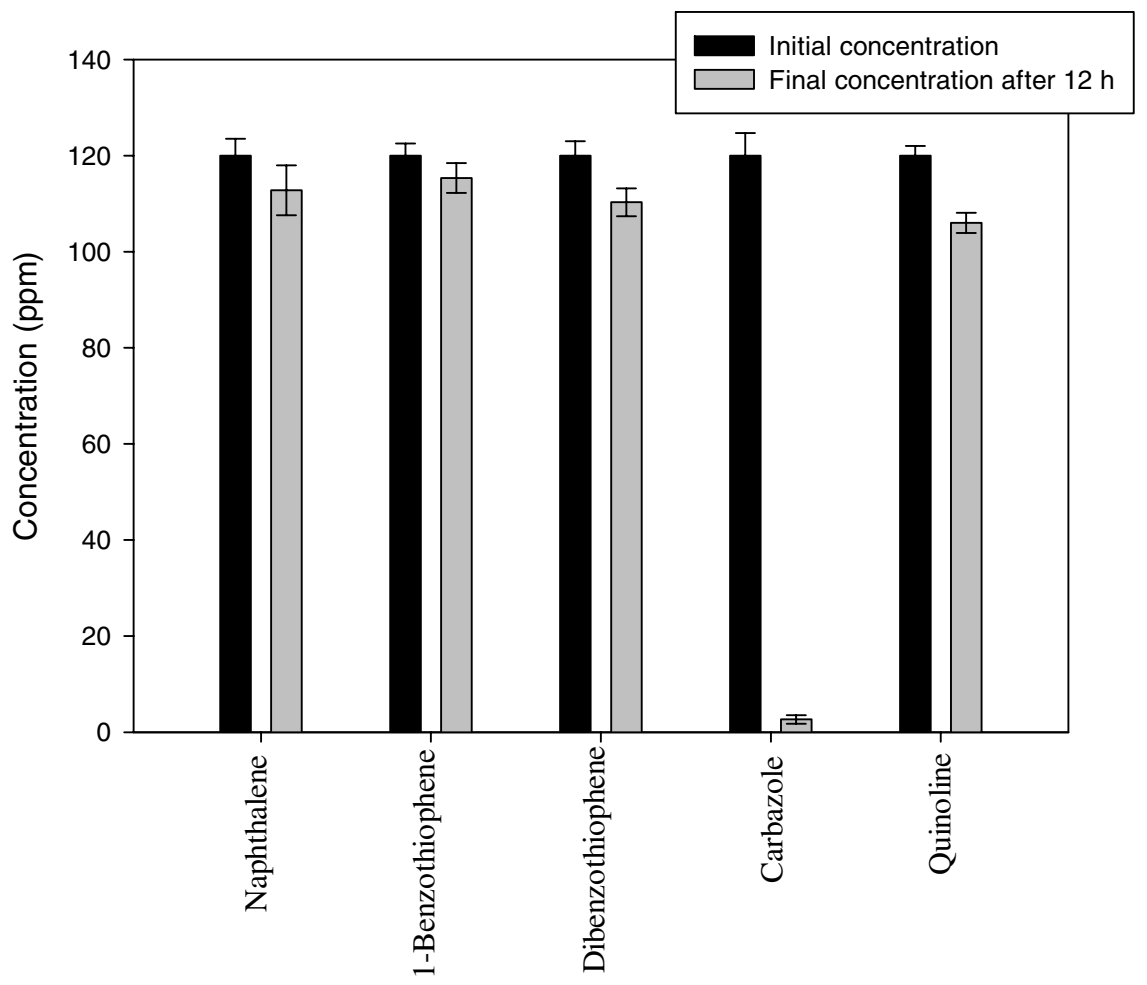

Figure S3. Adsorption selectivity of carbazole using carbazole-imprinted PBI nanofibers. 


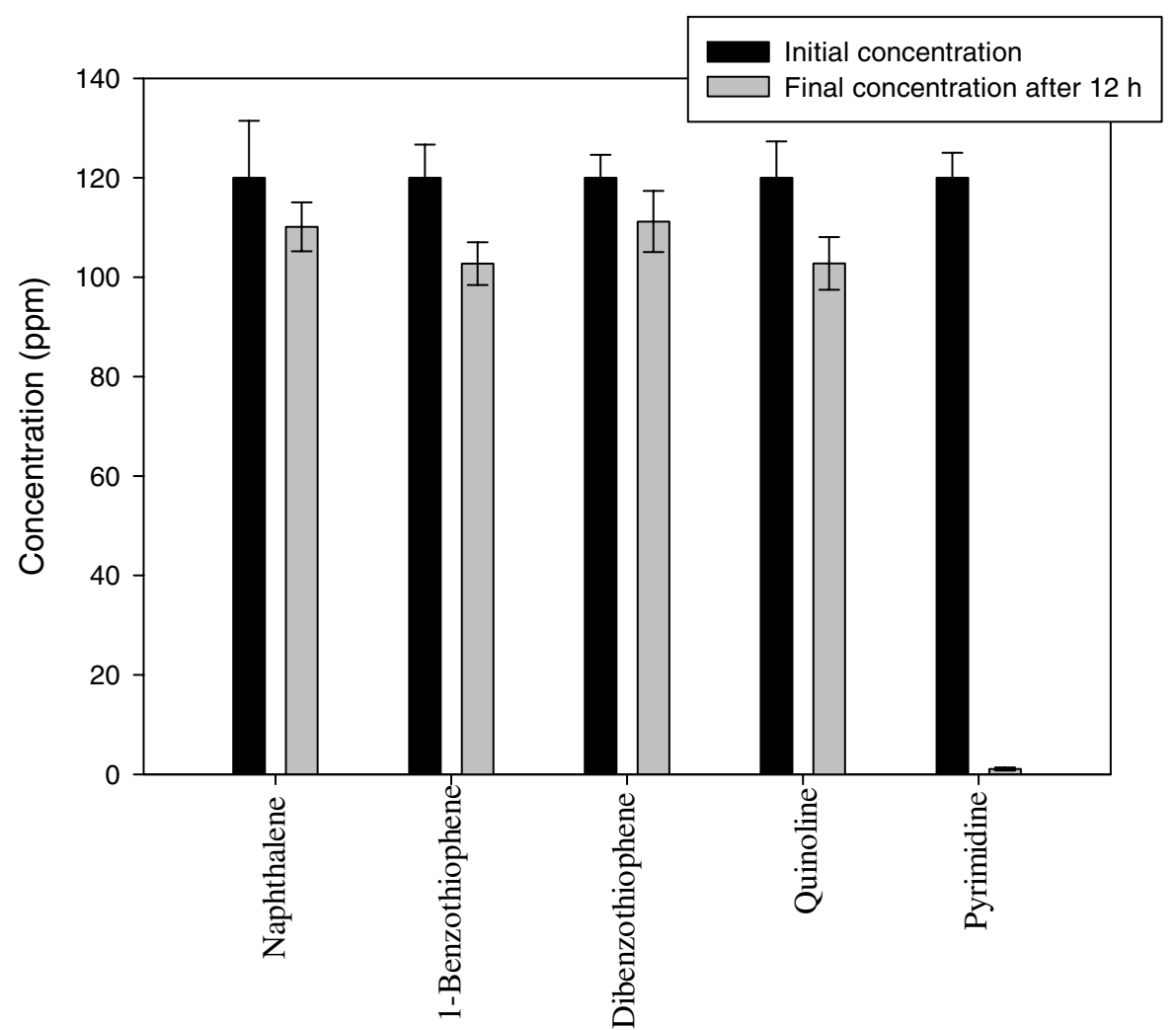

Figure S4. Adsorption selectivity of pyrimidine using pyrimidine-imprinted PBI nanofibers.

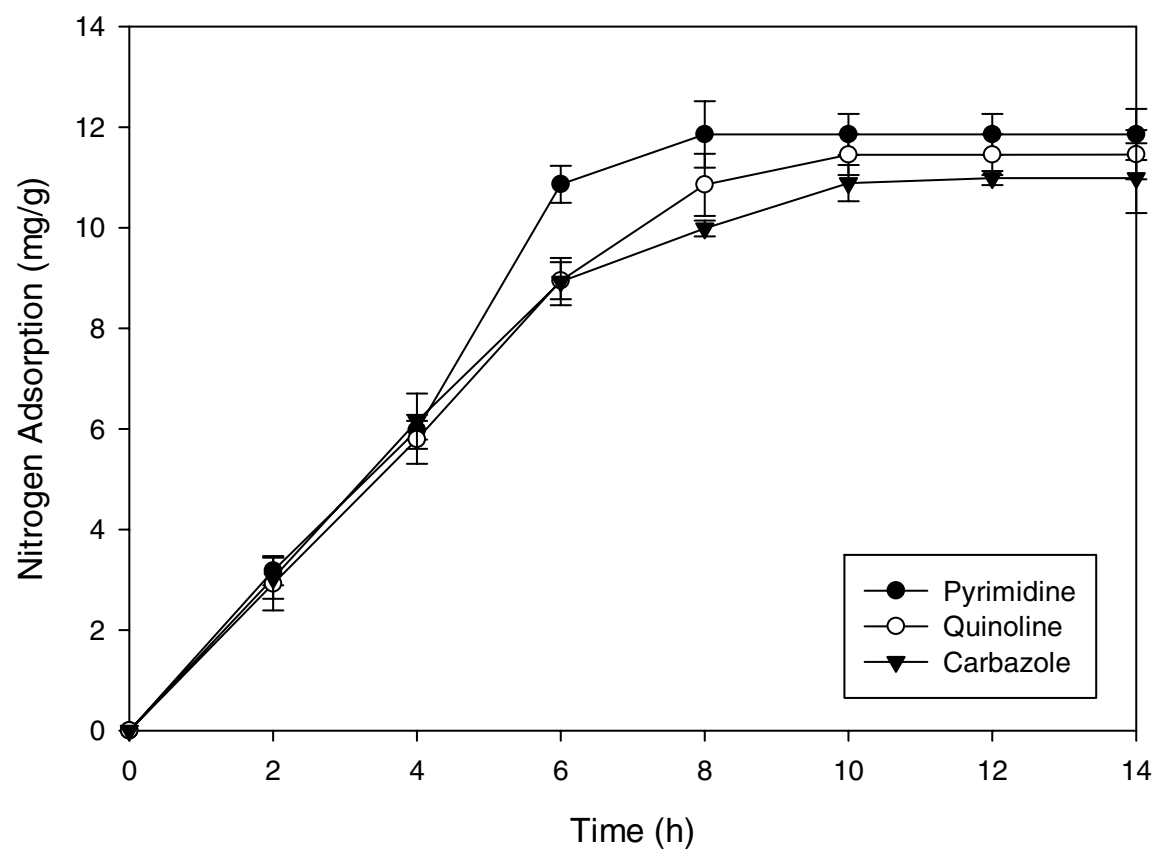

Figure S5. Kinetic of adsorption of the various nitrogen compounds over imprinted PBI nanofibers. 


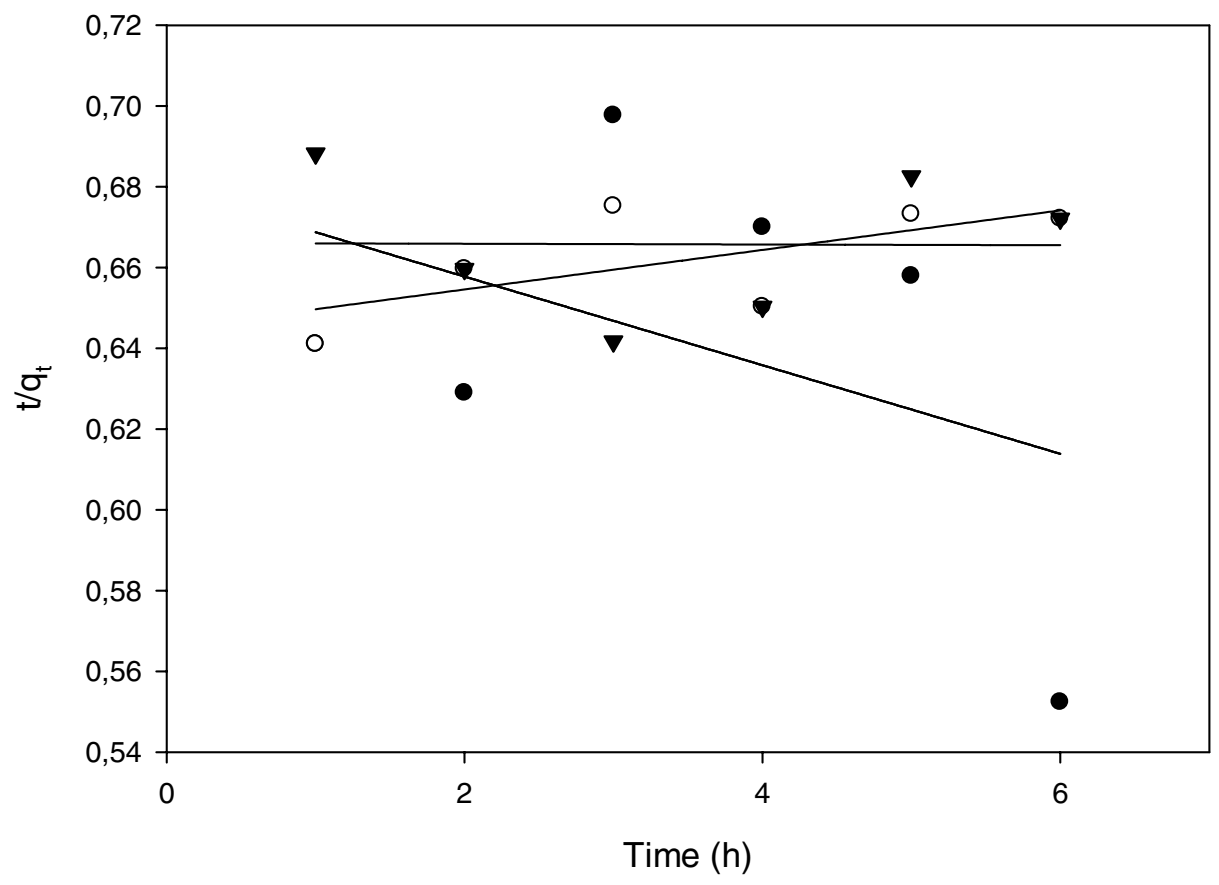

Figure S6. Pseudo-second-order plot of the nitrogen compounds (A) pyrimidine, (B) carbazole and (C) quinoline.

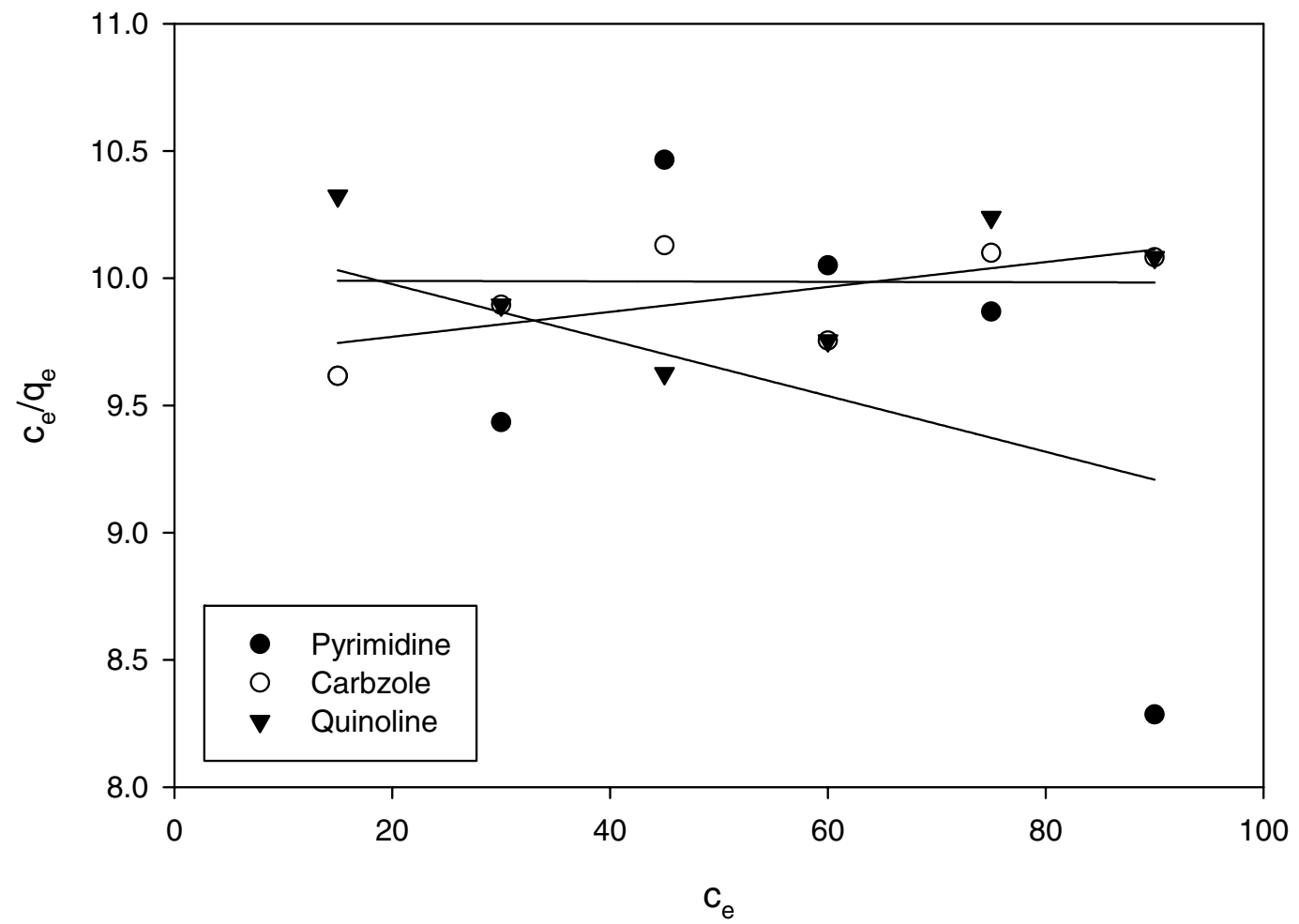

Figure S7 Langmuir plot of carbazole, quinoline and pyrimidine. 